\title{
Guideline of Prevention and Treatment for Chronic Hepatitis B (2015 Update)
}

\author{
Jinlin Hou*1, Guiqiang Wang ${ }^{2}$, Fusheng Wang ${ }^{3}$, Jun Cheng ${ }^{4}$, Hong Ren ${ }^{5}$, Hui Zhuang ${ }^{6}$, \\ Jian Sun ${ }^{1}$, Lanjuan $\mathrm{Li}^{7}$, Jie $\mathrm{Li}^{6}$, Qinghua Meng ${ }^{8}$, Jingmin $\mathrm{Zhao}^{9}$, Zhongping Duan ${ }^{10}$, \\ Jidong Jia ${ }^{11}$, Hong Tang ${ }^{12}$, Jifang Sheng ${ }^{7}$, Jie Peng ${ }^{1}$, Fengmin $\mathrm{Lu}^{6}$, Qing Xie ${ }^{13}$, Lai Wei*14; \\ Chinese Society of Hepatology, Chinese Medical Association; Chinese Society of Infectious \\ Diseases, Chinese Medical Association
}

\begin{abstract}
${ }^{1}$ Department of Infectious Diseases, Nanfang Hospital, Southern Medical University, Guangzhou, China; ${ }^{2}$ Department of Infectious Diseases, Center for Liver Diseases, Peking University First Hospital, Beijing, China; ${ }^{3}$ The Institute of Translational Hepatology, 302 Hospital of PLA, Peking University, Beijing, China; ${ }^{4}$ Center of Liver Diseases, Beijing Ditan Hospital, Capital Medical University, Beijing, China; ${ }^{5}$ Institute for Viral Hepatitis, the Key Laboratory of Molecular Biology for Infectious Diseases, the second Affiliated Hospital of Chongqing Medical University, Chongqing, China; ${ }^{6}$ Department of Microbiology of Peking University Health Science Center, Beijing, China; ${ }^{3}$ State Key Laboratory for Diagnosis and Treatment of Infectious Diseases, Collaborative Innovation Center for Diagnosis and Treatment of Infectious Diseases, the First Affiliated Hospital, College of Medicine, Zhejiang University, Hangzhou, China; ${ }^{8}$ Serious Illness Medicine Inpatient Area, Beijing Youan Hospital, Capital Medical University, Beijing, China; ${ }^{9}$ Department of Pathology, 302 Hospital of PLA, Peking University, Beijing, China; ${ }^{10}$ Artificial Liver Center, Beijing Youan Hospital, Capital Medical University, Beijing, China; ${ }^{11}$ Liver Research Center, Beijing Friendship Hospital, Capital Medical University, Beijing, China; ${ }^{12}$ Center of Infectious Diseases, West China Hospital of Sichuan University, Division of Infectious Diseases, State Key Laboratory of Biotherapy, Sichuan University, Chengdu, China; ${ }^{13}$ Department of Infectious Diseases, Shanghai Jiao Tong University School of Medicine Affiliated Ruijin Hospital, Shanghai, China; ${ }^{14}$ Hepatology Institute, Peking University People's Hospital, Beijing, China
\end{abstract}

Citation of this article: Hou J, Wang G, Wang F, Cheng J, Ren $\mathrm{H}$, Zhuang $\mathrm{H}$, et al. Guideline of prevention and treatment for chronic hepatitis B (2015 update). 2017;5(4):297-318. doi: $10.14218 /$ JCTH.2016.00019.

This guideline is established to standardize the prevention, diagnosis and antiviral therapy of chronic hepatitis $B(\mathrm{CHB})$. For other treatment regimens and methods involving $\mathrm{CHB}$, please refer to relevant guidelines and consensuses.

Keywords: Hepatitis B; Chronic; Treatment; Prevention; Guideline. Abbreviations: ADV, adefovir dipivoxil fumarate; AFP, alpha-fetoprotein; ALP, alkaline phosphatase; ALT, alanine aminotransferase; anti-HBc, hepatitis B core antibody; anti-HBe, hepatitis B e antibody; APRI, aspartate aminotransferase-toplatelet ratio index; ART, antiretroviral therapy; AST, aspartate aminotransferase; ccCDNA, covalently closed circular DNA; CDC, Center for Disease Control and Prevention; $\mathrm{CHB}$, chronic hepatitis $\mathrm{B}$; $\mathrm{CHO}$, Chinese hamster ovary; CMA, Chinese Medical Association; CT, computer tomography; DCP, des-gamma-carboxyprothrombin; ETV, entecavir; FIB-4, fibrosis-4; G-CSF, granulocyte colony-stimulating factor; GGT, gamma-glutamyl transpeptidase; GM-CSF, granulocyte-macrophage colony-stimulating factor; HAI, histological activity index; HBcAg, hepatitis B core antigen; $\mathrm{HBeAg}$, hepatitis $\mathrm{B}$ e antigen; HBIG, hepatitis B immune globulin; $\mathrm{HBsAg}$, hepatitis B surface antigen; $\mathrm{HBV}$, hepatitis $B$ virus; $\mathrm{HCC}$, hepatocellular carcinoma; HIV, human immunodeficiency virus; IgG, immunoglobulin G; IgM, immunoglobulin $M$; IFN- $\alpha$, interferon-alpha; INR, the international normalized ratio; LAM, lamivudine; LdT, telbivudine; LSM, liver stiffness measurement; mDcs, marrow-like dendritic cells; MRI, magnetic resonance imaging; NA, nucleos(t)ide analog; pDcs, plasmas-like dendritic cells; PIVKA-II, the protein induced by vitamin $\mathrm{K}$ absence or antagonist II; PT, prothrombin time; PTA, prothrombin activity; RIG-I, retinoic acid inducible gene-I; TBA, total bile acid; TDF, tenofovir disoproxil fumarate; TE, transient elastography; US, ultrasound; ULN, upper limit of normal; WHO, World Health Organization.

Received: 3 May 2016; Revised: 14 January 2017; Accepted: 16 January 2017 *Correspondence to: Jinlin Hou, Department of Infectious Diseases and Hepatology Unit, Nanfang Hospital, Southern Medical University, No. 1838 North Guangzhou avenue, Guangzhou 510515, China. E-mail: jlhousmu@163.com; Lai Wei, Peking University People's Hospital, Peking University Hepatology Institute, No. 11 Xizhimen South Street, Beijing 100044, China. E-mail: weilai@pkuph.edu.cn
The Chinese Society of Hepatology, Chinese Medical Association (CMA) and the Society of Infectious Diseases, CMA organized relevant native experts to establish this Guideline of Prevention and Treatment for Chronic Hepatitis B $\left(1^{\text {st }}\right.$ version) in 2005, and made the first revision in 2010. In the past 5 years, great progress has been made in the native and foreign fundamental and clinical research with respect to $\mathrm{CHB}$, necessitating additional revision of this guideline.

This guideline is intended to help clinicians make reasonable decisions in the diagnosis, prevention and antiviral therapy of CHB. However, it is not a compulsory standard and does not include or solve all problems in CHB diagnosis, treatment and management. Therefore, clinicians must develop comprehensive and reasonable diagnosis as well as treatment plan for individual patients according to his/ her own professional knowledge, clinical experience and available medical resources, based on a full understanding of best clinical evidence relating to this disease and careful consideration of the patient's specific condition and intention. We will continue to update and improve this guideline according to relevant native and foreign developments.

The overall evidence presented in this guideline is classified into A, B and C levels, and recommendation grades include grade 1 and grade 2 (Table 1 , revised according to GRADE classification)

Terms

Chronic hepatitis B virus (HBV) infection: Hepatitis $B$ surface antigen (HBsAg) seropositive status and/or HBV DNA positivity at 6 months or beyond.

CHB: Chronic necroinflammatory disease of the liver caused by persistent infection with HBV. $\mathrm{CHB}$ can be 
Hou J. et al: Guideline for CHB

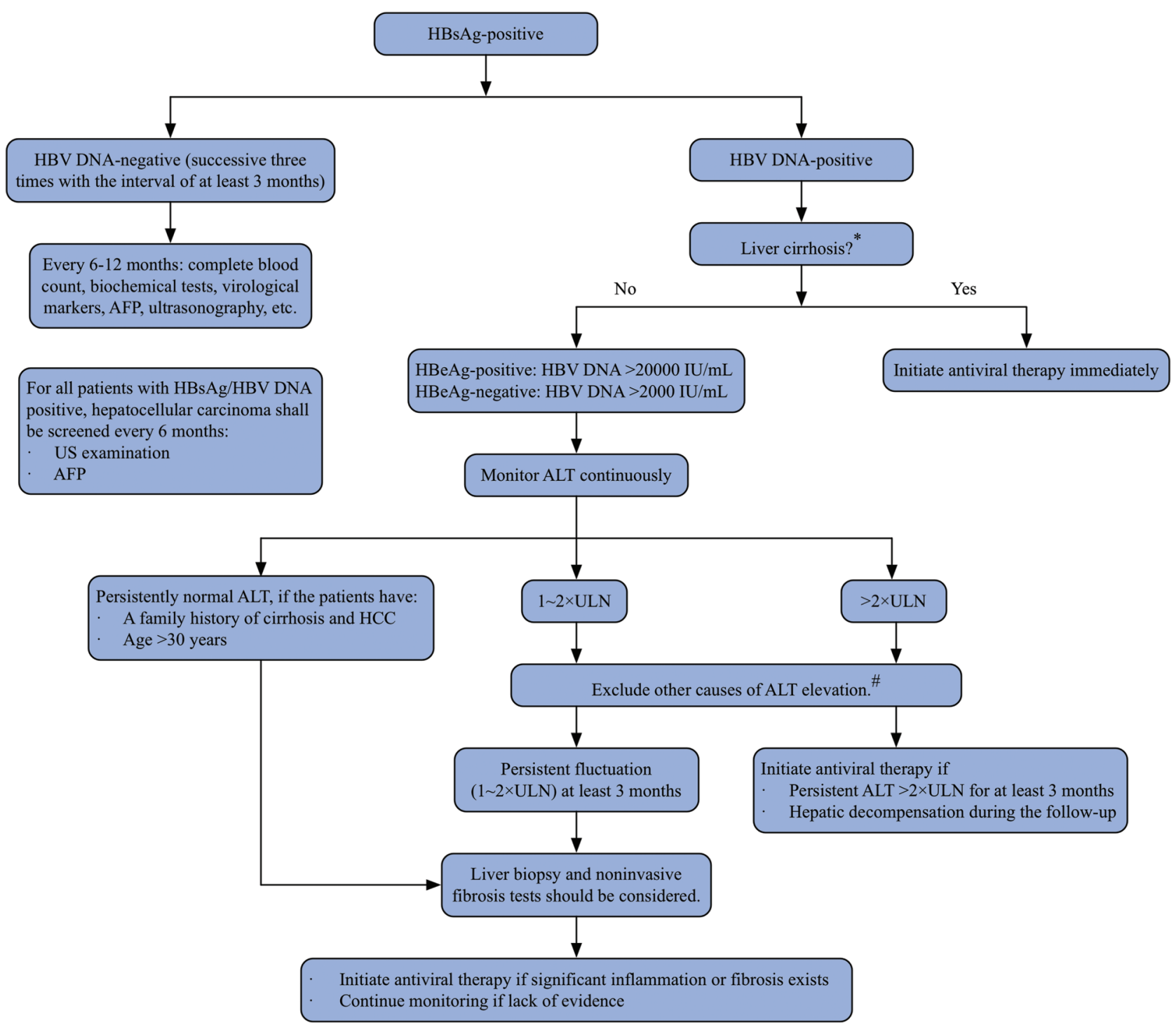

Fig. 1. Management for patients with chronic hepatitis $B$ virus infections.

*Cirrhosis: Histologic evidence or clinical features; HBV infection evidence confirmed by medical history and laboratory examination, with exclusion of other causes of cirrhosis (e.g., HCV infection, alcohol and drugs, etc.).

\#ALT elevation caused by other diseases, such as other pathogenic agents, use of drugs or alcohol, autoimmune hepatitis, and fatty liver disease, etc.

subdivided as hepatitis B e antigen (HBeAg)-positive and HBeAg-negative.

HBeAg-positive CHB: Serum HBsAg, HBeAg and HBV DNA are all positive, alanine aminotransferase (ALT) is persistently or repeatedly elevated, or hepatitis lesions are identified by liver biopsy.

HBeAg-negative CHB: Serum HBsAg and HBV DNA are positive, $\mathrm{HBeAg}$ is negative, ALT is persistently or repeatedly elevated, or hepatitis lesions are identified by liver biopsy.

Inactive HBsAg carrier: Serum $\mathrm{HBsAg}$ is positive, $\mathrm{HBeAg}$ is negative, HBV DNA is undetectable, serum ALT is normal (documented on at least three separate occasions, 3 months apart in 1 year); liver biopsy shows histological activity index (HAI) score of $<4$, or lesions are judged as mild according to other semi-quantitative scoring systems.
Resolved hepatitis B: With a past history of acute or $\mathrm{CHB}, \mathrm{HBsAg}$ is negative, anti-hepatitis B surface antibody (HBs) is positive or negative, anti-hepatitis $B$ core (aniti$\mathrm{HBC}$ ) is positive, HBV DNA is undetectable, and serum ALT is normal.

Acute exacerbation or flare of hepatitis B: Elevation of serum ALT level to more than 10-times the upper limit of normal (ULN) after excluding other factors resulting in liver injury.

Reactivation of hepatitis B: Marked increase in HBV replication ( $\geq 2$ log increase from baseline levels or a new appearance of HBV DNA to a level of $\geq 100 \mathrm{IU} / \mathrm{mL}$ ) in a person with previously stable or undetectable levels, or detection of HBV DNA with a level $\geq 20,000 \mathrm{IU} / \mathrm{mL}$ in a person with no baseline HBV DNA. Inflammatory necrosis reappearance in the liver and 
Hou J. et al: Guideline for $\mathrm{CHB}$

Table 1. Grading of evidence and recommendations

\begin{tabular}{ll}
\hline Grades & Detailed Descriptions \\
\hline Evidence quality & $\begin{array}{l}\text { Further research is unlikely to change our confidence in the estimate of effect } \\
\text { A: High }\end{array}$ \\
$\begin{array}{l}\text { B: Moderate } \\
\text { and may change the estimate }\end{array}$ \\
$\begin{array}{l}\text { Curther research is very likely to have an important impact on our confidence in the estimate of } \\
\text { effect and is likely to change the estimate }\end{array}$ \\
$\begin{array}{l}\text { Recommendation } \\
\text { 1: Strong }\end{array}$ \\
$\begin{array}{l}\text { Factors influencing strength of the recommendation included quality of the evidence, presumed } \\
\text { patient-important outcomes and cost }\end{array}$ \\
$\begin{array}{l}\text { Variability in preferences and values or greater uncertainty, more likely a weak recommendation } \\
\text { is warranted; recommendation is made with less certainty, with higher cost or resource } \\
\text { consumption }\end{array}$ \\
\hline
\end{tabular}

ALT elevation. This often occurs in inactive HBsAg carriers or patients with resolved hepatitis $B$, especially when receiving immunosuppressive therapy or chemotherapy.

HBeAg clearance: Loss of $\mathrm{HBeAg}$ in a person who was previously $\mathrm{HBeAg}$-positive.

HBeAg seroconversion: Loss of $\mathrm{HBeAg}$ and presence of anti-hepatitis $\mathrm{B}$ e antibody (anti-HBe) in a person who was previously $\mathrm{HBeAg}$-positive and anti-HBe-negative.

HBeAg reversion: Reappearance of $\mathrm{HBeAg}$ in a person who was previously $\mathrm{HBeAg}$-negative and anti-HBe-positive.

Histological response: Decline in inflammation and necrosis scores of hepatic histology by $\geq 2$ with no increase in fibrosis scoring, or decline in fibrosis scoring by $\geq 1$ in the METAVIR scoring system.

Complete response: Sustained virological response and HBsAg clearance or with anti-HBs seroconversion.

Clinical cure: Sustained virological response and $\mathrm{HBsAg}$ clearance or with anti-HBs seroconversion, ALT within the normal range, and mild or no lesions in the liver.

Primary nonresponse: Reduction of serum HBV DNA by $<1 \log _{10} \mathrm{IU} / \mathrm{mL}$ at 12 weeks or $<2 \log _{10} \mathrm{IU} / \mathrm{mL}$ at week 24 of nucleos(t)ide analog (NA) antiviral therapy in an adherent patient.

Suboptimal or partial virological response: Reduction of serum HBV DNA by $>2 \log _{10} \mathrm{IU} / \mathrm{mL}$ at week 24 but still being detectable at week 24 of NA therapy in an adherent patient.

Virological response: Serum HBV DNA level below the detection limit during therapy.

Virological breakthrough: For patients adherent with NA therapy, increase of serum HBV DNA by $>1 \log _{10} \mathrm{IU} / \mathrm{mL}$ from nadir of initial response during therapy, or conversion to positivity following negativity, as confirmed 1 month later using the same reagent.

Viral relapse: Serum HBV DNA >2,000 IU/mL after stopping treatment in patients with virological response, as confirmed 1 month later.

Clinical relapse: Viral relapse and ALT >2 $\times$ ULN; ALT elevation caused by other factors should be excluded.

Sustained off-treatment virological response: After the end of treatment, serum HBV DNA level sustained below the detection limit.

Drug resistance: Detection of mutations in the HBV genome that are known to confer resistance and develop during NAs therapy, which is defined as Genotypic
Resistance. Decreased susceptibility (determined by in vitro testing) to inhibition by antiviral drugs, associated with genotypic resistance, which is defined as Phenotypic Resistance. Drug-resistant mutation that arises for one antiviral drug can also show resistance to other antiviral drugs (either one or several), which is called Cross Resistance. Multidrug Resistance is defined as drug resistance to at least two different categories of NAs.

\section{Epidemiology and prevention}

\section{Epidemiology}

$\mathrm{HBV}$ is prevalent globally, and the prevalence of HBV infections is greatly different among different regions. It is reported by the World Health Organization (WHO) that about 2 billion people globally have ever been infected with HBV, among which 240 million people are infected with chronic $\mathrm{HBV}^{1}$ and about 650,000 persons die of hepatic failure, liver cirrhosis and hepatocellular carcinoma (HCC) caused by HBV infection every year. ${ }^{2}$ Among the patients with liver cirrhosis and HCC globally, the proportion of those caused by HBV infection is 30\% and $45 \%{ }^{2,3}$ respectively. Among patients with liver cirrhosis and $\mathrm{HCC}$ in China, the proportion of those caused by HBV infection is $60 \%$ and $80 \%{ }^{4}$ respectively. Due to popularization of the HBV vaccine, the number of acute HBV infections has become significantly decreased. Also, due to the aging of populations infected with $\mathrm{HBV}$, in combination with extensive application of antiviral therapy, the proportion of patients with $\mathrm{HBeAg}$-negative $\mathrm{CHB}$ has increased in recent years. ${ }^{5}$

The survey for national HBV serum prevalence conducted in 2006 showed that the HBsAg carrying rate of the general population aged $1-59$ years-old in China was $7.18 \% .^{6,7}$ Therefore, it is estimated that there were about 93 million people infected with HBV in China, among which were 20 million patients with $\mathrm{CHB}^{8}{ }^{8}$ The survey for national HBV serum prevalence among the population aged 1-29 years-old conducted in 2014 showed that the HBsAg prevalence rates in the population aged $1-4$ years-old, 5-14 years-old and $15-29$ yearsold were $0.32 \%, 0.94 \%$ and $4.38 \%$ respectively (China Center for Disease Control and Prevention (CDC)).

HBV transmits mainly via blood (e.g., unsafe injection, etc.), mother-to-child transmission and sexual contact. ${ }^{9}$ Since strict HBsAg and HBV DNA screenings are carried out 
for blood donors, HBV infections scarcely arise that are caused by blood transfusion or blood products. Transmission through damaged skin or mucous membranes is mainly caused by application of medical instruments that are not strictly disinfected, during invasive diagnosis and treatment operation, as well as unsafe injection, especially of drugs, etc. Other transmission routes include pedicuring, tattooing, piercing, accidental exposure in the work environment (i.e. for medical workers), sharing of shaver or toothbrush, etc. ${ }^{10}$ Mother-to-child transmission mainly arises in the perinatal period by contact with blood and fluid of HBV-positive mothers during the delivery period. With the application of $\mathrm{HBV}$ vaccine in combination with hepatitis $B$ immune globulin (HBIG), the rate of mother-to-child transmission has been greatly reduced. ${ }^{10}$ The risk of HBV infections is increased for the case of non-protected sexual contact with HBV-positive patients, especially for those who have several sexual partners.

HBV does not transmit via the respiratory tract nor the digestive tract; thus, HBV cannot be infected via daily learning, working and life contacts: e.g., working in the same office (including sharing computers and other office supplies), contact through shaking hands and hugging, living in the same dormitory, dining in the same restaurant and toilet sharing and other non-blood exposure contacts. It has not been found by epidemic and experimental studies that HBV can transmit via hematophagous insects (mosquitos and other pests). ${ }^{9}$

\section{Prevention}

\section{Prevention via HBV vaccine}

$\mathrm{HBV}$ vaccination is the most effective measure to prevent HBV infections, mainly targeting newborns, ${ }^{11}$ followed by previously unvaccinated infants, children and adolescents under the age of 15 years-old, and high-risk population members (e.g., health care workers, staff with frequent blood exposures, workers in nurseries and kindergartens, patients receiving organ transplantation, patients receiving frequent blood transfusions or blood products, immunocompromised patients, household contacts with an HBsAg-positive person, men who have sex with men, persons with multiple sexual partners and injection-drug users, etc.).

The primary hepatitis $B$ immunization series conventionally consists of three doses of vaccine; the first dose of vaccine is given at birth, the second dose in the 1st month of life and the third dose in the 6th month of life. The birth-dose of HBV vaccine should be administered preferably within 24 hours of birth, as soon as possible. The vaccine is administered by intramuscular injection into the anterolateral aspect of the buttock or into the deltoid muscle (for newborns) and into the middle deltoid muscle (for children and adults).

HBV vaccine alone has been shown to be $87.8 \%$ efficacious in the prevention of mother-to-infant transmission of HBV. ${ }^{12}$ All infants born to HBsAg-positive women should receive HBIG ( $\geq 100 \mathrm{IU})$ and concurrent recombinant yeast HBV vaccine $(10 \mu \mathrm{g})$ at different injection sites within 24 hours after birth (preferably within 12 hours after birth), followed by the second and third dose of HBV vaccine in the 1st month and 6th month of life, respectively, thus significantly improving the efficacy of prevention. ${ }^{13,14}$ Infants who have received HBIG and HBV vaccine within 12 hours after birth can be breastfed by HBsAg-positive mothers. ${ }^{10}$

Maternal HBV DNA level is the most critical factor associated with mother-to-infant transmission of HBV. ${ }^{13}$ High level of maternal HBV DNA ( $>10^{6} \mathrm{IU} / \mathrm{mL}$ ) brings about more possibilities of mother-to-infant transmission of HBV. It has recently been demonstrated that antiviral therapy during the second and third trimester of pregnancy in these women with high viral load can reduce serum HBV DNA level and then improve the efficacy of prevention of HBV from mother to baby. ${ }^{14-17}$ For more details, please refer to "Antiviral Therapy for Special Population-Treatment of Pregnancy-Related Situations".

Recombinant yeast HBV vaccine $(10 \mu \mathrm{g})$ can be administered for infants born to HBsAg-negative women. Recombinant yeast HBV vaccine $(10 \mu \mathrm{g})$ or Chinese hamster ovary $(\mathrm{CHO})$ recombinant HBV vaccine $(20 \mu \mathrm{g})$ should be administered for previously unvaccinated children. Three doses of recombinant yeast HBV vaccine $(20 \mu \mathrm{g})$ or $\mathrm{CHO}$ recombinant $\mathrm{HBV}$ vaccine $(20 \mu \mathrm{g})$ are recommended for adults. As for immunocompromised patients or non-responders, the dose (e.g., $60 \mu \mathrm{g}$ ) and frequency of vaccine should be increased. As for individuals who did not respond to a three-dose immunization series, one additional dose $(60 \mu \mathrm{g})$ or three additional doses $(20 \mu \mathrm{g})$ recombinant yeast $\mathrm{HBV}$ vaccine can be administered, and serum anti-HBs should be detected in 1-2 months after the second dose of vaccine. If still no response occurs, one additional dose $(60 \mu \mathrm{g})$ of recombinant yeast HBV vaccine should be injected.

Protection against HBV infection has persisted for at least 12 years among responders after the implementation of universal vaccination. ${ }^{18}$ Thus, anti-HBs detection or booster immunization is not necessary for general populations. As for the high-risk population, however, anti-HBs can be monitored and booster vaccination is needed in the case of anti-HBs level reaching $<10 \mathrm{mIU} / \mathrm{mL}^{19}$

\section{Prevention after accidental exposure}

When damaged skin or mucous membrane is accidentally exposed to blood and fluid of patients with HBV infections, the following recommended measures should be applied:

1. Serological testing: HBV DNA, HBsAg, anti-HBs, HBeAg, anti-HBe, anti-HBc, and liver function should be detected immediately, and re-examination should be carried out within 3 months and 6 months, respectively.

2. Active and passive immunization: As for the population previously vaccinated and with anti-HBs positivity, no special management is needed. As for individuals who were unvaccinated previously or whose anti-HBs is $<10$ $\mathrm{mIU} / \mathrm{mL}$ or unknown after vaccination, HBIG 200 400 IU and concurrent HBV vaccine $(20 \mu \mathrm{g})$ at different injection sites should be administered immediately, followed by the second dose $(20 \mu \mathrm{g})$ and third dose $(20 \mu \mathrm{g})$ of vaccine after 1 month and 6 months, respectively.

\section{Management of patients and carriers}

As for persons with confirmed HBsAg-positive status, reports should be submitted to the local CDC according to regulations, and serum $\mathrm{HBsAg}$, anti-HBC and anti-HBs tests should be performed for family members of the patient; finally, HBV vaccine should be administered for susceptible persons (for whom all the three markers are negative).

The infectivity level of HBV patients and carriers mainly depends on serum HBV DNA level, while it is not associated with serum ALT, aspartate aminotransferase (AST) or bilirubin levels. As to follow-up details for HBV patients and carriers, 
please refer to the section of "Follow-up for Patients" in this guideline. Patients with chronic HBV infections and inactive HBsAg carriers should not donate blood or organs or take up occupations or types of work stipulated by the state regulations, but they can be engaged in normal working and learning with periodical medical follow-up.

\section{Blocking transmission routes}

It is critical to extensively promote safe injection (including tools for acupuncture and moxibustion) and abide strictly by standard precaution principles of nosocomial infection management. Tools used in the service industry, including hairdressing, shaving, pedicuring, puncturing and tattooing and so on, should be strictly disinfected. It is also important to pay attention to personal hygiene and to not share shavers and toothbrushes with others. Persons whose sexual partners are HBsAg-positive should receive the HBV vaccine or use condoms; in case the health condition of the sexual partner is unknown, condoms must be used to prevent HBV and other hematogenous or sexually transmitted diseases. As for pregnant women with HBsAg-positive status, the chance of newborns exposed to maternal bloods should be reduced by avoiding amniotic cavity puncture and maintaining the completeness of placenta.

Recommendation 1: Infants born to HBsAg-positive women should receive HBIG ( $\geq 100 \mathrm{IU})$ and concurrent recombinant yeast HBV vaccine $(10 \mu \mathrm{g})$ at different injection sites within 24 hours after birth (preferably within 12 hours after birth), followed by the second and third doses of HBV vaccine in the 1st month and 6th month of life respectively, thereby significantly improving the efficacy of prevention (A1).

Recommendation 2: Catch-up vaccination should be administered for previously unvaccinated children, using recombinant yeast HBV vaccine $(10 \mu \mathrm{g})$ or Chinese hamster ovary $(\mathrm{CHO})$ recombinant $\mathrm{HBV}$ vaccine $(20 \mu \mathrm{g})(\mathrm{A} 1)$.

Recommendation 3: Infants received HBIG and HBV vaccine within 12 hours after birth can be breastfed by HBsAg-positive mothers (B1).

Recommendation 4: As for immunocompromised patients or nonresponders, the dose (e.g., $60 \mu \mathrm{g}$ ) and frequency of vaccine should be increased. As for individuals who did not respond to the three-dose immunization series, one additional dose $(60 \mu \mathrm{g})$ or three additional doses $(20 \mu \mathrm{g})$ recombinant yeast $\mathrm{HBV}$ vaccine can be administered, and serum anti-HBs should be detected in 1-2 months after the second dose of vaccine. If still no response occurs, one additional dose $(60 \mu \mathrm{g})$ of recombinant yeast HBV vaccine should be injected (A1).

\section{Etiology}

HBV is a partial double-stranded enveloped virus of the Hepadnaviridae family. The genome has a length of about $3.2 \mathrm{~Kb}$ and encodes the $\mathrm{HBsAg}$, hepatitis $\mathrm{B}$ core antigen $(\mathrm{HBCAg}), \mathrm{HBeAg}$, viral polymerase and $\mathrm{HBx}$ proteins. $\mathrm{HBV}$ is possessed of strong resistance, but it can be inactivated at $65^{\circ} \mathrm{C}$ for $10 \mathrm{~h}$, at $100^{\circ} \mathrm{C}$ for 10 minutes or by high pressure vapors. In addition, HBV can be effectively inactivated by ethylene oxide, glutaraldehyde, peroxyacetic acid and iodophor.

Recent studies have demonstrated that the sodium taurocholate cotransporting polypeptide (NTCP) in the hepatic cell membrane is a cellular receptor required for HBV infection. ${ }^{20}$ After HBV invades hepatic cells, partial double-strand circular
HBV DNA extends the plus-strand in the cell nucleus to repair the fissure region in the plus-strand with minus-strand DNA as the template, to form covalently closed circular DNA (cccDNA). Then cccDNA serves as the template for transcription of viral mRNAs with different lengths, which is pregenome RNA and codes various antigens of HBV. The half-life period of cccDNA is so long that it is difficult to be completely eliminated from the body, thus playing an important role in chronic infections.

There are at least nine genotypes for HBV (i.e. A-J), ${ }^{21}$ of which $B$ and $C$ are the predominant genotypes in China. HBV genotype is associated with disease progression and responses to IFN- $\alpha$ treatment. Patients infected with genotype $\mathrm{B}$ are less likely to develop chronic hepatitis, liver cirrhosis and HCC compared to those with genotype C. ${ }^{22-24}$ In HBeAgpositive patients, $\mathrm{HBV}$ genotype $\mathrm{B}$ has a higher response rate to interferon-alpha (IFN- $\alpha$ ) based therapy than genotype $C$, and HBV genotype $A$ has better responses to IFN- $\alpha$ treatment than genotype $D$ patients. Viral quasispecies and serum HBV RNA may play an important role in $\mathrm{HBeAg}$ seroconversion, immune clearance and responses to antiviral therapy. ${ }^{25-27}$

\section{Natural history and pathogenesis}

\section{Natural History}

The natural history of HBV infections depends on the dynamic interaction between virus, host and the environment. The age when hosts are infected with HBV is the most critical factor that has an influence on chronicity. Among patients who acquire HBV infection at birth and during the infant period, $90 \%$ and $25 \% \sim 30 \%$ respectively develop chronic infections, only $5 \% \sim 10 \%$ of persons who acquire HBV infection after 5 years of age progress to chronic infections. ${ }^{28}$ In China, most of the patients with HBV infections are infected at birth or the infant period.

The natural history of patients who acquire HBV infection in the infant period is divided into four phases, namely the immune tolerance phase, immune clearance phase, inactive or non(low)-replicating phase and reactivation phase. ${ }^{29}$

Immune tolerance phase: Serum HBsAg-positive and HBeAg-positive, high levels of serum HBV DNA, normal serum ALT, with liver histological evidence of mild or no liver necroinflammation, and no progression or only slow progression of hepatic fibrosis. ${ }^{30}$

Immune clearance phase: Serum HBV DNA level $>2000$ $\mathrm{IU} / \mathrm{mL}$, persistent or intermittent elevation in serum ALT, and moderate or severe inflammation and necrosis observed in hepatic histology; hepatic fibrosis rapidly progresses, with some patients developing liver cirrhosis and hepatic failure.

Non(low)-replicating phase: Serum HBeAg-negative and anti-HBe-positive, low or undetectable serum HBV DNA level, ALT within the normal range, no inflammation or only mild inflammation evidence in hepatic histology; for patients in this stage who have HBeAg seroconversion before development of significant hepatic diseases, risks of liver cirrhosis and HCC are significantly decreased.

Reactivation phase: About $5 \%-15 \%$ of patients in the inactive stage experience hepatitis flares once or several times, with manifestations including negativity for $\mathrm{HBeAg}$, positivity for anti-HBe, moderate and high HBV DNA replication (>2000 IU/ $\mathrm{mL}$ ), sustained or repeatedly abnormal ALT and development of $\mathrm{HBeAg}$-negative $\mathrm{CHB} ;{ }^{31} \mathrm{HBeAg}$ reversion is possible.

Not all patients with HBV infections will experience all of the above four phases. There is no immune tolerance phase 
for most patients infected with HBV at the adolescent and adult periods, but they directly enter into the immune clearance phase.

Spontaneous HBeAg seroconversion mainly occurs in the immune clearance phase, and the annual incidence rate is $2 \% \sim 15 \%$. In patients with elevated $A L T$, the incidence rates of $\mathrm{HBV}$ infections with genotypes $A$ and $B$ under the age of 40 are high. ${ }^{29,32}$ Following HBeAg seroconversion, HBsAg clearance appears in $0.5 \% \sim 1.0 \%$ of patients every year. ${ }^{33}$ It is found that after HBsAg has disappeared for 10 years, cccDNA can be detected in the liver of about $14 \%$ of those patients. ${ }^{34}$ In the case of patients older than 50 years-old or complicated with HCV or hepatitis D virus (HDV) infections, progression into liver cirrhosis can occur when HBsAg has disappeared, and although the probability of development into $\mathrm{HCC}$ is low, it is still possible. ${ }^{35}$

The incidence rate of liver cirrhosis is $2 \% \sim 10 \%$ in patients with $\mathrm{CHB}^{36}$ and risk factors include those related to the host (i.e. older age, male, being $>40$ years-old when the HBeAg seroconversion occurs, ${ }^{37}$ having ALT persistently elevated ${ }^{38}$ ), the virus (i.e. HBV DNA $>2000 \mathrm{IU} / \mathrm{mL}, \mathrm{HBeAg}$ remaining positive, ${ }^{39}$ genotype $\mathrm{C}$, coinfection with HCV, HDV or human immunodeficiency virus (HIV) and the environment (i.e. alcohol and obesity ${ }^{36,40}$ ). The annual incidence rate of compensated cirrhosis that has developed into hepatic decompensation is $3 \% \sim 5 \%$, and the 5 -year survival rate of hepatic decompensation is $14 \% \sim 35 \%$. 35

The annual incidence rate of $\mathrm{HCC}$ is $0.5 \% \sim 1.0 \%$ in noncirrhosis patients with HBV infections. ${ }^{36}$ The annual incidence rate of $\mathrm{HCC}$ is $3 \% \sim 6 \%$ in cirrhosis patients. ${ }^{41-43}$ Risk factors of HCC are similar to those of liver cirrhosis. In addition, suffering from liver cirrhosis and/or diabetes mellitus, immediate relatives having a history of $\mathrm{HCC}$, high serum $\mathrm{HBsAg}$ level and aflatoxin are related with the development of $\mathrm{HCC}^{36,40,44-48}$ Low HBsAg level often reflects that hosts have good immune control for HBV replication and infections. For patients with negative HBeAg, low HBV DNA level $(<2000 \mathrm{IU} / \mathrm{mL})$ and HBV infections of genotype B or $\mathrm{C}$, and high HBsAg level (HBsAg $\geq 1000 \mathrm{IU} / \mathrm{mL}$ ) will increase risk of HCC. ${ }^{47,48}$

\section{Pathogenesis}

The pathogenesis of $\mathrm{CHB}$ is complicated and has not been completely clarified to date. It is shown by a large quantity of studies that HBV cannot directly kill hepatic cells, and immune response caused by HBV is a major pathogenesis for injury of hepatic cells and inflammation. Repeated inflammation existence is an important factor for patients with $\mathrm{CHB}$ developing into liver cirrhosis and even HCC.

Innate immunity plays a role in the initial stage of HBV infection, and induces subsequent specific immune responses. Nonspecific immune responses become dysregulated in patients with chronic HBV infection. ${ }^{49,50} \mathrm{HBV}$ can suppress the intensity of nonspecific immune responses through their own HBeAg and HBx proteins, and other protein components, as well as through interference of two antiviral signal transduction pathways in the host, namely those involving the Toll-like receptors and retinoic acid inducible gene-I (RIG-I). Patients with CHB often present with low frequency of marrow-like dendritic cells (mDcs) and plasmas-like dendritic cells (pDcs) in peripheral blood. Dysmaturity exists among the mDcs. Moreover, the capacity of pDcs to produce IFN- $\alpha$ is significantly lowered, and the capacity of the body to eliminate viruses and to induce function of HBV-specific
T lymphocytes is reduced, which negatively impacts viral elimination.

HBV-specific immune responses play a leading role in HBV clearance. ${ }^{51}$ MHC1 molecule restrictive CD8+ cytotoxic T lymphocytes induce liver apoptosis and secretion of IFN- $\gamma$ and suppresses the expression and replication of HBV genes in other hepatic cells through an cellular lysis mechanism. ${ }^{52}$ In the event of chronic infections, HBV-specific T lymphocytes are liable to apoptosis, oligo-clones exist, the function and proliferation capacity of secreting cytokines are significantly decreased, T lymphocyte function is exhausted and HBV is persistently replicated. ${ }^{52}$

\section{Laboratory examination}

\section{HBV serological test}

HBV serological markers include HBsAg, anti-HBs, HBeAg, anti-HBe, anti-HBc and anti-HBc-immunoglobulin M (IgM). HBsAg positivity indicates HBV infections. Anti-HBs is a protective antibody, and anti-HBs positivity indicates immunity to HBV and is observed in patients with resolved hepatitis B infections and in subjects who are inoculated with the hepatitis $B$ vaccine. Anti-HBc-IgM positivity is mostly found in patients with acute hepatitis $B$ and reactivation of $\mathrm{CHB}$. The major anti$\mathrm{HBC}$ antibody is an immunoglobulin $\mathrm{G}$ ( $\mathrm{IgG}$ ) antibody; as long as persons are infected with $\mathrm{HBV}$, whether viruses are eliminated or not, this antibody is positive in most cases. Among $\mathrm{HBeAg}$-positive patients with $\mathrm{CHB}$, the quantitation of baseline anti-HBc antibody has a predictive value for the efficacy of pegylated (peg)-IFN- $\alpha$ and NA based therapy. ${ }^{54,55}$ Serum HBsAg quantitation can also be used to predict disease progression, antiviral efficacy and prognosis. ${ }^{9,56,57}$

\section{HBV DNA, genotype and mutation detection}

HBV DNA quantitative determination is mainly used to determine the viral replication level of chronic HBV infections. It is also used to select indications of antiviral therapy and estimate the efficacy. The real-time quantitative PCR method is recommended because of its high sensitivity and accuracy.

HBV genotype and drug-resistant mutant strain detection is most commonly carried out by (1) genotype-specific primer PCR method, (2) gene sequence determination method, and (3) linear probe reverse hybridization.

\section{Biochemical examination}

Serum ALT and AST: Serum ALT and AST levels can generally reflect the degree of hepatic cell injury, and are most commonly used.

Serum bilirubin: Serum bilirubin level is related with bile metabolism and excretion degree, and the main reasons for bilirubin elevation are hepatic cell injury, intrahepatic and extrahepatic biliary tract obstruction, and hemolysis. Serum bilirubin level of patients with hepatic failure can be progressively elevated, with increase of $\geq 1$ time ULN each day, and divergence phenomenon may appear (i.e. bilirubin elevation and decrease of ALT and AST).

Serum albumin and globulin: Serum albumin and globulin reflect synthetic functions of the liver. Patients with $\mathrm{CHB}$, liver cirrhosis and hepatic failure present with reduced serum albumin. 
Prothrombin time (PT) and prothrombin activity (PTA): PT is an important indicator to reflect synthetic functions of liver coagulation factors, and is often expressed by the international normalized ratio (INR), which has great value for the judgment of disease progression and prognosis.

Gamma-glutamyl transpeptidase (GGT): Serum GGT of healthy persons is mainly derived from the liver. This enzyme is mildly or moderately elevated in the event of acute hepatitis, chronic active hepatitis and decompensated liver cirrhosis. It is significantly increased in cases of intrahepatic and extrahepatic cholestasis, by all causes.

Serum alkaline phosphatase (ALP): ALP is excreted via the hepatobiliary system. Therefore, when ALP is excessively secreted or obstructed, changes of ALP appear in blood. Disease progression, prognosis and clinical efficacy are judged by the dynamic changes in ALP observation clinically.

Serum total bile acid (TBA): Minimal serum bile acid content is found in peripheral blood of healthy persons. In the event of injury of hepatic cells or intrahepatic and extrahepatic occlusion, an abnormality is observed in bile acid metabolism, and the total bile acid is elevated.

Cholinesterase: Cholinesterase can reflect synthetic functions of the liver and provide reference value for understanding hepatic emergency functions and reserve function.

Alpha-fetoprotein (AFP): Serum AFP and its variants are important indicators for the diagnosis of HCC. Attention should be paid to the amplitude of AFP increase, dynamic changes and the growth and decline relation between AFP, ALT and AST; comprehensive analysis should be implemented, combining clinical manifestations and imaging examinations of the liver. ${ }^{58-61}$

Vitamin K: Vitamin K deficiency or the protein induced by vitamin $\mathrm{K}$ absence or antagonist II (PIVKA-II); also known as des-gamma-carboxyprothrombin (DCP) is another important indicator for the diagnosis of HCC, and can be used complementary to AFP. ${ }^{62-64}$

\section{Non-invasive diagnosis of hepatic fibrosis}

Aspartate aminotransferase-to-platelet ratio index (APRI): APRI scoring can be used for the evaluation of liver cirrhosis. For adults, an APRI score $>2$ indicates that patients have developed liver cirrhosis. The APRI calculation formula is $\left[(\right.$ AST/ULN $) \times 100 /$ PLT $\left.\left(10^{9} / \mathrm{L}\right)\right] .^{65}$

Fibrosis-4 (FIB-4) index: FIB-4 is based on a calculation using ALT, AST and PLT and the age of patients. It can be used for estimating diagnosis and stage of liver fibrosis with chronic hepatitis. The calculation formula is $[($ age $\times$ AST $) \div$ (square root of platelet $\times$ ALT)] .

Transient elastography (TE): As a mature and noninvasive examination methodology, TE is characterized by simple operation and good repeatability, and can accurately identify mild hepatic fibrosis and advanced hepatic fibrosis or early liver cirrhosis. ${ }^{66,67}$ However, the success rate of TE measurement is affected by obesity, size of the intercostal space, experience of operators, and its measured value is affected by hepatic necroinflammation, cholestasis and fatty degeneration, among other factors. Since abnormality in bilirubin has a significant influence on the efficiency of TE diagnosis, TE examination should be performed when the bilirubin level is normal. The judgment of TE results should be combined with consideration of the ALT level and other parameters of patients, and TE in combination with other serological parameters can improve the efficiency of the diagnosis. 68,69

Clinical application of TE: For patients with normal bilirubin level and who are naïve to antiviral therapy, the value of liver stiffness measurement (LSM) $\geq 17.5 \mathrm{kPa}$ is diagnosed as liver cirrhosis, and LSM $\geq 12.4 \mathrm{kPa}$ (ALT $<2 \times$ UNL is 10.6 $\mathrm{kPa}$ ) can be diagnosed as advanced hepatic fibrosis; LSM $<10.6 \mathrm{kPa}$ means that liver cirrhosis may be excluded. LSM $\geq 9.4 \mathrm{kPa}$ can be diagnosed as significant hepatic fibrosis. LSM $<7.4 \mathrm{kPa}$ indicates that advanced hepatic fibrosis can be excluded. For patients with LSM of $7.4 \sim 9.4 \mathrm{kPa}$, liver biopsy should be considered. For patients with normal transaminase and bilirubin levels, LSM $\geq 12.0 \mathrm{kPa}$ leads to diagnosis of liver cirrhosis, LSM $\geq 9.0 \mathrm{kPa}$ leads to diagnosis of advanced liver fibrosis, LSM $<9.0 \mathrm{kPa}$ leads to exclusion of liver cirrhosis, and LSM $<6.0 \mathrm{kPa}$ leads to exclusion of advanced hepatic fibrosis. For patients with LSM of $6.0 \sim 9.0 \mathrm{kPa}$, if clinical decisions cannot be made, liver biopsy can be considered. ${ }^{69,70}$

\section{Imaging diagnosis}

The main purposes of imaging examination are to monitor the clinical progression of $\mathrm{CHB}$, to determine whether liver cirrhosis exists, to identify space-occupying lesions and differentiate the nature of such, and (especially) to monitor and diagnose HCC.

Abdominal ultrasound (US) examination: Due to simple and intuitive operation, non-invasive nature and low price, US examination has become an important method that is commonly used for hepatic examination. This method can assist in determining the shape of the liver and the spleen, major vessels in the liver, and whether there is any liver space-occupying lesion, but this method can be limited by instruments and equipment, anatomic site, technique used, experience of the operators, etc.

Electronic computer tomography (CT) imaging: At present, CT is an important imaging method for the diagnosis and differential diagnosis of hepatic lesions, and can be used to observe the shape of the liver, to determine whether liver cirrhosis exists or not, and to identify spaceoccupying lesions in a timely manner and differentiate the nature of such. Dynamic contrast-enhanced multi-stage scanning has high sensitivity and specificity for HCC diagnosis.

Magnetic resonance imaging (MRI) or MR: Characterized by no radioactive radiation, high tissue resolution and multi-directional and multi-sequence imaging, the display and resolution of MRI or MR on tissue structural changes of the liver (e.g., hemorrhage, necrosis, fatty degeneration and intrahepatic nodules) are superior to that of CT and US. Dynamic contrast-enhanced multi-stage scanning and special enhancer imaging can better differentiate benign and malignant intrahepatic space-occupying lesions than $\mathrm{CT}^{58}$

\section{Pathological diagnosis}

The purpose of liver biopsy is to evaluate the degree of hepatic lesions in $\mathrm{CHB}$ patients, to exclude other hepatic diseases, to predict prognosis and to monitor responses to therapy.

Pathological characteristics of CHB are described here. Different levels of inflammation are found in the portal area and its surrounding areas, and infiltrative inflammatory cells concentrate on mononuclear cells, mainly including the lymphocytes and a few plasmocytes and macrophages. 
Inflammatory cell aggregation often results in enlargement in the portal area, and can lead to interboard apoptosis and hepatocyte necrosis forming interface inflammation (which used to be known as piecemeal necrosis). Degeneration, necrosis and apoptosis can be found in hepatic cells of folioles, and ground-glass hepatocytes can be observed. Necrotic forms of hepatocytes include the features of spotted and focal necrosis, bridging necrosis and fusion necrosis, etc.

Apoptotic hepatocytes can form apoptotic bodies that become enhanced with the inflammation activity. Although a minority of $\mathrm{CHB}$ cases will not develop into hepatic fibrosis, most can result in presenting with different degrees of fibrous enlargement in the portal area and the formation of fibrous septum, because of the excessive deposition of extracellular matrix due to sustained viral infection and the inflammation activity. Masson three-color staining and reticular fiber staining can be used to evaluate the degree of hepatic fibrosis. Further progression of significant fibrosis (METAVIR stage $\geq F 2$ ) and advanced fibrosis (METAVIR stage $\geq F 3$ ) can result in disorders of hepatic lobular structure, nodular regeneration of hepatocytes, and formation of the pseudolobule structure, which is cirrhosis. After elimination or suppression of viruses and resolution of inflammatory lesions, hepatic fibrosis and liver cirrhosis take on different degrees of histological reversion. ${ }^{71,72}$

The expression of HBsAg and HBcAg can be detected by immumohistochemical staining. HBV DNA or cccDNA in liver tissue can be detected by nucleic acid in situ hybridization or the PCR method, if there is clinical need. ${ }^{73}$

The internationally common METAVIR ${ }^{74}$ system (Tables 2 and 3 ) is recommended for grading of hepatic necroinflammation and staging of fibrosis in CHB. In addition, computerassisted digitized image analysis is applied to determine the collagen proportionate area of liver tissues, which can be used for quantitative evaluation of hepatic fibrosis in clinical trial but not used in clinical practice at present. ${ }^{75,76}$

\section{Clinical diagnosis}

According to results of serological, viral and biochemical tests as well as other clinical and auxiliary examinations in HBVinfected patients, chronic HBV infection can be classified into:

\section{Chronic HBV carriers}

Most are young patients with $\mathrm{HBsAg}, \mathrm{HBeAg}$ and HBV DNA positivity in the immune tolerance phase. Continuous follow-up consisting of 3 times within 1 year, with an interval of at least 3 months, showing that serum ALT and AST levels are always within normal range, that there is generally high HBV DNA level and no lesions or only mild hepatic necroinflammatory observed by hepatic histological examinations. $9,57,77,78$

\section{HBeAg-positive CHB}

Serum HBsAg-positive, HBeAg-positive, HBV DNA-positive, sustained or repeated abnormality in ALT level or hepatic necroinflammatory features observed by hepatic histological examinations.

\section{HBeAg-negative CHB}

Serum HBsAg-positive and HBeAg-negative continuously, HBV DNA-positive, sustained or repeated abnormality in ALT level or hepatic necroinflammatory features observed by hepatic histological examinations.

\section{Inactive HBsAg carrier}

Serum HBsAg-positive, HBeAg-negative, anti-HBe-positive or negative, HBV DNA level below the detection limit or <200 IU/ $\mathrm{mL}$, continuous follow-up for more than three times within 1 year, with an interval of at least 3 months, showing that both ALT and AST are always within the normal range. Hepatic histological examination shows that HAI score is $<4$ or having mild lesions identified according to other semiquantitative scoring systems.

\section{Occult CHB}

Serum HBsAg is positive, but HBV DNA in serum and/or hepatic tissue is positive, with clinical manifestations of $\mathrm{CHB}$ also existing. Besides the HBV DNA positivity, serum anti-HBs, anti-HBe and/or anti-HBc may also be positive; however, about $20 \%$ of occult CHB patients are serological marker-negative. Diagnosis is implemented mainly through HBV DNA detection, especially for patients with sustained positivity for anti-HBc.

\section{Hepatitis B-related liver cirrhosis}

The conditions necessary to establish clinical diagnosis of HBVrelated cirrhosis include: histological or clinical evidence of liver cirrhosis; evidence of HBV infection, with clear etiology

Table 2. METAVIR system and histological inflammation activity scoring

\begin{tabular}{|c|c|c|c|}
\hline Histologic activity & Interface inflammation & Inflammatory necrosis in folioles & Activity of inflammation \\
\hline & 0 (none) & 0 (none or mild) & 0 (none) \\
\hline & 0 & 1 (moderate) & 1 (mild) \\
\hline \multirow[t]{5}{*}{$A^{*}$} & $\begin{array}{l}0 \\
1 \text { (mild) } \\
1\end{array}$ & $\begin{array}{l}2 \text { (severe) } \\
0,1 \\
2\end{array}$ & $\begin{array}{l}2 \text { (moderate) } \\
1 \\
2\end{array}$ \\
\hline & 1 & 0,1 & 1 \\
\hline & 2 (moderate) & 0,1 & 2 \\
\hline & 2 & 2 & 3 (severe) \\
\hline & 3 (severe) & $0,1,2$ & 3 \\
\hline
\end{tabular}

* Based on the degrees of interface inflammation and inflammatory necrosis in folioles. 
Hou J. et al: Guideline for $\mathrm{CHB}$

Table 3. METAVIR system and fibrosis stage scoring

\begin{tabular}{|c|c|}
\hline Lesions & $\begin{array}{l}\text { Fibrosis } \\
\text { stage scores }\end{array}$ \\
\hline No fibrosis & 0 \\
\hline $\begin{array}{l}\text { Fibrous enlargement in the portal } \\
\text { area, but no fibrous septum is formed }\end{array}$ & 1 \\
\hline $\begin{array}{l}\text { Fibrous enlargement in the portal } \\
\text { area and few fibrous septa are formed }\end{array}$ & 2 \\
\hline $\begin{array}{l}\text { Multiple fibrous septa are formed, } \\
\text { but no cirrhotic nodules }\end{array}$ & 3 \\
\hline Liver cirrhosis & 4 \\
\hline
\end{tabular}

(other common etiologies of liver cirrhosis are HCV infection, alcohol and drug use, etc., and should be definitively excluded by medical history or corresponding examinations. ${ }^{79}$

Liver cirrhosis is classified into compensated stage and decompensated stage, according to whether or not the main complications exist clinically. For compensated cirrhosis, evidence of synthesis function disorders of hepatocytes or portal hypertension are obtained by imaging, biochemical or hematological examinations, or histology and complies with the diagnosis of liver cirrhosis; no symptoms such as esophageal and gastric varices rupture hemorrhage, ascites or hepatic encephalopathy or severe complications will be found. For decompensated cirrhosis, evidence of esophageal and gastric varices rupture hemorrhage, hepatic encephalopathy, ascites or other severe complications is found. ${ }^{80}$

In order to predict disease progression more accurately and judge the death risk of patients with liver cirrhosis, complications of liver cirrhosis can be evaluated according to the five-stage classification method, whereby stage 1 is indicated by no varicosity and no ascites, stage 2 is indicated by varicosity but no hemorrhage or ascites, stage 3 is indicated by ascites but no hemorrhage, and with or without varicosity, stage 4 is indicated by hemorrhage, with or without ascites, and stage 5 is indicated by septicopyemia. Stages 1 and 2 represent compensated liver cirrhosis and stages 3 to 5 represent decompensated liver cirrhosis. The 1-year case fatality rates of stages $1,2,3,4$ and 5 are $<1 \%, 3 \% \sim 4 \%$, $20 \%, 50 \%$ and $>60 \%$ respectively. The occurrence of complications is closely related with prognosis and death risk in patients with liver cirrhosis. ${ }^{79,81,82}$

\section{Goals of treatment}

The goals of treatment are to improve quality of life and survival of the infected person by maximally suppressing HBV replication in a sustained manner, reducing hepatic necroinflammation and hepatic fibrosis, and delaying and decreasing hepatic failure, progression of hepatic decompensation, HCC and other complications; these achievements improve the quality of life and prolong survival time. During the treatment, clinical cure of $\mathrm{CHB}$ should be pursued as far as possible for eligible patients (with cure evidenced by sustained virological

Table 4. Summary of efficacy of various antiviral agents for patients with HBeAg-positive chronic hepatitis B

\begin{tabular}{|c|c|c|c|c|c|c|}
\hline Antiviral drug & $\begin{array}{l}\mathrm{HBeAg} \\
\text { seroconversion } \\
\text { rate }\end{array}$ & $\begin{array}{l}\text { Undetectable } \\
\text { HBV DNA } \\
\text { rate }\end{array}$ & $\begin{array}{l}\text { ALT } \\
\text { normalization } \\
\text { rate }\end{array}$ & $\begin{array}{l}\text { HBsAg } \\
\text { loss rate }\end{array}$ & $\begin{array}{l}\text { Resistance } \\
\text { rate }\end{array}$ & Reference(s) \\
\hline \multicolumn{7}{|l|}{$\begin{array}{l}\text { Short-term treatment: } \\
\text { 48-52 weeks }\end{array}$} \\
\hline Peg-IFN- $\alpha-2 a$ & 32 & 14 & 41 & 3 & NA & 125 \\
\hline Peg-IFN- $\alpha-2 b$ & 29 & 7 & 32 & 7 & NA & 126 \\
\hline LAM & $16 \sim 18$ & $36 \sim 44$ & $41 \sim 72$ & $0 \sim 1$ & $11 \sim 32$ & $\begin{array}{l}104,125 \\
127-129\end{array}$ \\
\hline $\mathrm{LdT}$ & 22 & 60 & 77 & 0.5 & 5.0 & 129 \\
\hline ETV & 21 & 67 & 68 & 2 & 0 & 104 \\
\hline ADV & $12 \sim 18$ & $13 \sim 21$ & $48 \sim 54$ & 0 & 0 & 130 \\
\hline TDF & 21 & 76 & 68 & 3 & 0 & 109 \\
\hline \multicolumn{7}{|l|}{$\begin{array}{l}\text { Long-term treatment: } \\
2-8 \text { years }\end{array}$} \\
\hline $\begin{array}{l}\text { Peg-IFN- } \alpha, 3 \text { years after } \\
\text { drug discontinuation }\end{array}$ & 35 & 19 & - & 11 & NA & 88 \\
\hline LAM, 5 years & 22 & - & 58 & - & 70.8 & 122 \\
\hline LdT, 2 years & 30 & 56 & 70 & 1.3 & 25.1 & 116 \\
\hline ETV, 5 years & - & 94 & 80 & $\begin{array}{l}5 \text { for } 2 \\
\text { years }\end{array}$ & 1.2 & 106,131 \\
\hline ADV, 5 years & 29 & 55 & 77 & - & 14.6 & 132 \\
\hline TDF, 8 years & 31 & 98 & - & 13 & 0 & 110 \\
\hline
\end{tabular}

Data are presented as \%, unless otherwise indicated.

Note: - indicates no related data. 
Hou J. et al: Guideline for CHB

Table 5. Summary of efficacy of various antiviral agents for patients with HBeAg-negative chronic hepatitis B

\begin{tabular}{|c|c|c|c|c|c|}
\hline Antiviral drug & $\begin{array}{l}\text { Undetectable } \\
\text { HBV DNA rate }\end{array}$ & $\begin{array}{l}\text { ALT } \\
\text { normalization } \\
\text { rate }\end{array}$ & $\begin{array}{l}\text { HBsAg loss } \\
\text { rate }\end{array}$ & $\begin{array}{l}\text { Resistance } \\
\text { rate }\end{array}$ & Reference(s) \\
\hline \multicolumn{6}{|l|}{$\begin{array}{l}\text { Short-term treatment: } \\
\text { 48-52 weeks }\end{array}$} \\
\hline Peg-IFN- $\alpha-2 a$ & 19 & 59 & 3 & NA & 133 \\
\hline LAM & $72 \sim 73$ & $71 \sim 79$ & 0 & 10.7 & $129,133,134$ \\
\hline LdT & 88 & 74 & 0 & 2.2 & 129 \\
\hline ETV & 90 & 78 & 0 & 0 & 105 \\
\hline ADV & $51 \sim 63$ & $72 \sim 77$ & 0 & 0 & 109,135 \\
\hline TDF & 93 & 76 & 0 & 0 & 109 \\
\hline \multicolumn{6}{|l|}{$\begin{array}{l}\text { Long-term treatment: } \\
\text { 2-8 years }\end{array}$} \\
\hline $\begin{array}{l}\text { Peg-IFN- } \alpha, 3 \text { years after } \\
\text { drug discontinuation }\end{array}$ & 18 & 31 & 8 & NA & 136 \\
\hline LAM & NA & NA & NA & NA & - \\
\hline LdT, 2 years & 82 & 78 & 0.5 & 10.8 & 116 \\
\hline ETV & NA & NA & NA & NA & - \\
\hline ADV, 5 years & 67 & 69 & 5 & 29 & 120 \\
\hline TDF, 8 years & 99 & - & 1.1 & 0 & 110 \\
\hline
\end{tabular}

Data are presented as \%, unless otherwise indicated.

Note: - indicates no related data; NA indicates data not available.

response after the end of treatment, loss of HBsAg, ALT normalization and improvement in hepatic histology).

\section{Endpoints of treatment}

Ideal endpoint: In both $\mathrm{HBeAg-positive} \mathrm{and} \mathrm{HBeAg-negative}$ patients, off-therapy HBsAg loss is sustained, with or without seroconversion to anti-HBs.

Satisfactory endpoint: Induction of sustained offtherapy virological response, with ALT normalization in both $\mathrm{HBeAg}$-positive (with sustained anti-HBe seroconversion) and $\mathrm{HBeAg}$-negative patients.

Basic endpoint: If sustained off-therapy response is not achievable, then a maintained virological remission (undetectable HBV DNA by a sensitive PCR assay) should be attempted under long-term antiviral therapy.

\section{Indications of antiviral therapy}

Indications of antiviral therapy are generally based mainly on the combination of serum HBV DNA levels, serum ALT levels and severity of liver diseases. ${ }^{78,83,84}$ Indications for treatment that should also be taken into account are age, family history, concomitant diseases and other factors, to perform comprehensive evaluation on risks of disease progression, thereby helping to decide whether it is necessary to start antiviral therapy (Fig. 1). Dynamic evaluation has more clinical significance than a single detection. HBeAg-positive patients should be observed for 3-6 months after a one-time ALT level elevation. If no spontaneous $\mathrm{HBeAg}$ seroconversion occurs, the patient should be considered for antiviral therapy.

It is recommended that patients who receive the antiviral therapy should meet all the following conditions: ${ }^{9,80,83,85}$
HBV DNA level: HBeAg-positive patients, having HBV DNA $\geq 20000 \mathrm{IU} / \mathrm{mL}$ (equivalent to $10^{5}$ copies $/ \mathrm{mL}$ ). HBeAg-negative patients, having HBV DNA $\geq 2000 \mathrm{IU} / \mathrm{mL}$ (equivalent to $10^{4}$ copies/mL).

ALT level: General requirement for sustained elevation in ALT level at $\geq 2 \times$ ULN. If IFN therapy is applied, the ALT level should be $\leq 10 \times$ ULN, and serum total bilirubin should be $<2 \times$ ULN under general circumstances.

Because of the high risk of disease progression in patients with sustained HBV DNA positivity but who do not meet the above treatment standards and who present with one of the following conditions, antiviral therapy should be considered:

1. Significant hepatic inflammation (above grade 2 ) or fibrosis exists, especially above grade 2 hepatic fibrosis (A1);

2. If ALT level is persistently between 1 to $2 \times$ ULN, especially for patients aged $>30$ years, it is recommended to perform liver biopsy or non-invasive test. Treatment may be started in patients with significant inflammation or fibrosis (B2);

3. ALT level is persistently normal (when monitored every 3 months), patient aged $>30$ years and has liver cirrhosis or familial history of HCC. It is recommended to perform liver biopsy or non-invasive test. Treatment may be started in patients with significant inflammation or fibrosis (B2);

4. When objective evidence of liver cirrhosis exists, regardless of ALT and HBeAg status, active antiviral therapy is recommended (A1).

It should be noted that ALT elevation caused by coinfection with other pathogens, use of drugs and/or alcohol, or immunity and other factors should be excluded. It is also 
Hou J. et al: Guideline for $\mathrm{CHB}$

important to pay attention to transiently normal ALT after hepatoprotective drugs are used.

\section{Conventional IFN- $\alpha$ and Peg-IFN- $\alpha$ therapy}

Conventional IFN- $\alpha$ and peg-IFN- $\alpha$ have been approved to treat CHB in China.

\section{Regimens and efficacy of common IFN- $\alpha$ and Peg-IFN- $\alpha$ therapy}

The efficacy of conventional IFN- $\alpha$ therapy is moderate for patients with $\mathrm{CHB}$. HBeAg seroconversion, HBV DNA suppression and biochemical responses to peg-IFN- $\alpha$ therapy are higher than that with conventional IFN- $\alpha .{ }^{86}$ Several key international multicenter randomized control clinical trials have shown that for $\mathrm{HBeAg}$-positive patients treated with pegIFN- $\alpha-2 a$ therapy for 48 weeks $(180 \mu \mathrm{g} /$ week), the HBeAg seroconversion rate was $32 \% \sim 36 \%$ at week 24 of follow-up after drug discontinuation, and that the HBeAg seroconversion rates were $44.8 \%$ and $61.1 \%$ for patients with baseline ALT level of 2-5 $\times$ ULN or baseline ALT of 5-10 $\times$ ULN, respectively; the HBsAg seroconversion rate was $2.3 \%-3 \%$ at week 24 after drug discontinuation, respectively. ${ }^{80,87}$ It was also shown that for patients with $\mathrm{HBeAg}$-positive $\mathrm{CHB}$, peg-IFN$\alpha-2 b$ was able to produce similar HBV DNA suppression, $\mathrm{HBeAg}$ seroconversion rate and $\mathrm{HBsAg}$ clearance rate; ${ }^{80}$ the HBsAg clearance rate was $11 \%$ at 3 years after the drug discontinuation. ${ }^{88}$

Among patients with HBeAg-negative CHB (60\% Asians) receiving peg-IFN- $\alpha-2 a$ therapy for 48 weeks, $43 \%$ achieved HBV DNA $<2000 \mathrm{IU} / \mathrm{mL}$ at week 24 after treatment, and $42 \%$ at 48 weeks after the end of treatment; the HBsAg clearance rate was $3 \%$ at 24 weeks after the end of treatment, and increased to $8.7 \%$ at 3 years post-treatment, ${ }^{80}$ with further increase to $12 \%$ at 5 years post-treatment. ${ }^{89}$ There are also studies that have confirmed prolonging therapy to 2 years could improve the response rate, ${ }^{90,91}$ but from the view of pharmaco-economics, prolonged treatment is not recommended at this stage due to the increased side effects and economic burdens.

\section{Peg-IFN- $\alpha$ and NAs combination or sequential therapy}

It is uncertain whether peg-IFN- $\alpha$ in combination with NA therapy can improve the efficacy. HBeAg seroconversion, $\mathrm{HBsAg}$ clearance, virological responses and biochemical responses at the end of treatment are superior for combination therapy compared to peg-IFN- $\alpha$ alone, but the sustained response rate is not significantly improved. ${ }^{92-94} \mathrm{~A}$ study showed that for peg-IFN- $\alpha$ therapy, entecavir (ETV) add-on did not improve either the $\mathrm{HBeAg}$ seroconversion rate or the HBsAg clearance rate. ${ }^{95}$

After NAs are applied to lower the viral load, the HBeAg seroconversion rate and decrease in $\mathrm{HBsAg}$ achieved with pegIFN- $\alpha$ combination or sequential therapy are superior to those of NA monotherapy. ${ }^{96-100}$ One multicenter randomized openlabel study showed that for patients with $\mathrm{HBeAg}$-positive $\mathrm{CHB}$ who used ETV monotherapy for 9 36 months and achieved HBV DNA $<1000$ copies/mL and HBeAg $<100 \mathrm{PEIU} / \mathrm{mL}$, the HBeAg seroconversion rate $(14.9 \%$ vs. $6.1 \%)$ and $\mathrm{HBsAg}$ clearance rate $(8.5 \%$ vs. $0 \%)$ were higher in patients who received the peg-IFN- $\alpha-2$ a sequential treatment for 48 weeks than in patients who continued to use the ETV monotherapy, respectively. ${ }^{97}$ Another study showed that for patients with HBeAg positivity who achieved HBV DNA $<200 \mathrm{IU} / \mathrm{mL}$ and HBeAg clearance after they received NA therapy [lamivudine (LAM), ETV, or adefovir dipivoxil (ADV)] for $1 \sim 3$ years, the HBsAg clearance rate and seroconversion rate was $16.2 \%$ and $12.5 \%{ }^{98}$ respectively after receipt of peg-IFN- $\alpha-2$ a sequential therapy for 48 weeks. However, peg-IFN or sequential therapy can bring more side effects and economic burdens, and there is need for further evaluation from the view of pharmacoeconomics.

\section{Predictive factors of efficacy of IFN- $\alpha$ based antiviral therapy}

\section{Predictive factors before treatment}

The $\mathrm{HBeAg}$ seroconversion rate is higher for patients with $\mathrm{HBeAg}$-positive $\mathrm{CHB}$ who present with the following factors and receive peg-IFN- $\alpha$ therapy: 1 ) HBV DNA $<2 \times 10^{8} \mathrm{IU} / \mathrm{mL}$; 2) high ALT level; 3) genotype A or B infection; 4) low baseline $\mathrm{HBsAg}$ level and higher baseline anti-HBc; 5) necroinflammatory score of liver biopsy above G2. There are not effective factors to predict virological responses before treatment for patients with $\mathrm{HBeAg}$-negative $\mathrm{CHB} .{ }^{78}$ Patients with antiviral indications, relatively young age (including adolescents), with the intention to deliver babies in a short period of years, with the intention to complete short-term treatment, and who are antiviral treatment-naïve can be given priority for peg-IFN- $\alpha$ therapy.

\section{Predictive factors during treatment}

HBsAg and HBV DNA quantitative levels at week 24 of treatment for patients with $\mathrm{HBeAg}$-positive $\mathrm{CHB}$ are predictive factors for response to treatment. ${ }^{78}$ In the case of $\mathrm{HBsAg}$ $<1500 \mathrm{IU} / \mathrm{mL}$ at week 24 of peg-IFN- $\alpha$ treatment, continuing monotherapy till week 48 can achieve high HBeAg seroconversion rate. ${ }^{87}$ If $\mathrm{HBsAg}$ quantification is still higher than $20,000 \mathrm{IU} / \mathrm{mL}$ through the 24-week therapy regimen, it should be considered to stop the peg-IFN- $\alpha$ therapy ${ }^{101}$ and switch to NA therapy.

For $\mathrm{HBeAg}$-negative patients with $\mathrm{CHB}$, decrease in $\mathrm{HBsAg}$ and HBV DNA levels during the treatment period are predictive factors for sustained virological response after the end of treatment. ${ }^{89}$ If no decrease is found in HBsAg and decline of HBV DNA level from the baseline $<2 \log _{10} \mathrm{IU} / \mathrm{mL}$ is observed, it should be considered to stop the peg-IFN- $\alpha$ therapy. ${ }^{102,103}$ For details, please refer to "Recommendations for Antiviral Therapy".

\section{Management on side effects of IFN- $\alpha$ based therapy}

Influenza-like syndrome is manifested by fever, headache, myalgia and fatigue, etc.; thus, IFN- $\alpha$ can be injected before sleeping or an analgesic-antipyretic can be taken at the same time.

If transient peripheral cytopenia, such as absolute neutrophil count $\leq 0.75 \times 10^{9} / \mathrm{L}$ and/or platelet $<50 \times 10^{9} / \mathrm{L}$, the dose of IFN- $\alpha$ therapy should be reduced. Re-examination should be implemented in 1 2 weeks. If recovered, the dose should be increased to the original amount. In case of absolute neutrophil count $\left(\leq 0.5 \times 10^{9} / \mathrm{L}\right.$ and/or platelet $<25 \times 10^{9} / \mathrm{L}$, IFN should be discontinued. For patients with significant decrease in neutrophil count, it is recommended to apply 
granulocyte colony-stimulating factor (G-CSF) or granulocytemacrophage colony-stimulating factor (GM-CSF) therapy.

Mental disorders are manifested by depression, delusional disorders and severe anxiety, as well as other types of mental disorders. For patients with severe symptoms, IFN- $\alpha$ should be immediately stopped, and further diagnosis and treatment should be implemented via consultation with professional physicians with mental and psychological specialization, if necessary.

Some patients with autoimmune diseases present with autoantibodies, while only few patients suffer from thyroid diseases, diabetes mellitus, thrombocytopenia, psoriasis, vitiligo, rheumatoid arthritis and systemic lupus erythematosus-like syndrome, etc. Consultation and treatment should be implemented by physicians of the related department, and drugs should be discontinued for patients with severe symptoms.

In case of other rare adverse events, including renal injuries, cardiovascular complications, retinopathy, hearing loss and interstitial pneumonia, etc., IFN- $\alpha$ therapy should be discontinued.

\section{Contraindications of IFN- $\alpha$ therapy}

Absolute contraindications of IFN- $\alpha$ therapy include pregnancy or intention to be pregnant in the short term, psychiatric history (i.e. history of schizophrenia or severe depression, etc.), uncontrolled epilepsy, decompensated liver cirrhosis, uncontrolled autoimmune diseases, severe infection, retinal disease, heart failure, chronic obstructive pulmonary diseases and other underlying diseases. Relative contraindications of IFN- $\alpha$ therapy include thyroid disease, a past history of depression, uncontrolled diabetes mellitus, hypertension, neutrophil count $<1.5 \times$ $10^{9} / \mathrm{L}$ and/or platelet count $<90 \times 10^{9} / \mathrm{L}$ before treatment.

\section{NA therapy and monitoring}

\section{Efficacy of five NAs}

\section{ETV}

Phase III clinical trial results showed that the rates of undetectable HBV DNA (<300 copies/mL), HBeAg seroconversion, normalization of ALT and improvement in hepatic histology were $67 \%, 21 \%, 68 \%$ and $72 \%{ }^{104}$ respectively at week 48 of ETV therapy for patients with HBeAg-positive CHB. On the other hand, the rates of undetectable HBV DNA $(<300$ copies $/ \mathrm{mL}$ ), normalization of ALT and improvement in hepatic histology were $90 \%, 78 \%$ and $70 \%$ respectively at week 48 of ETV therapy for patients with $\mathrm{HBeAg}$-negative $\mathrm{CHB} .{ }^{105} \mathrm{An}$ ETV 5-year follow-up study showed that the rates of undetectable HBV DNA ( $<300$ copies $/ \mathrm{mL}$ ) and normalization of ALT were $94 \%$ and $80 \%$ respectively for patients with HBeAg-positive CHB. ${ }^{106}$

The cumulative drug-resistance incidence rate of 5-year ETV therapy was $1.2 \%$ for NA treatment-naïve patients with $\mathrm{CHB}$ (HBeAg-positive or -negative). However, among patients with LAM resistance, the cumulative genotypic resistance incidence rate of 5-year ETV therapy was increased to $51 \% .{ }^{107}$ Liver histological studies on the application of ETV therapy for 5 years showed that $55 / 57$ (88\%) of patients could achieve improvement in hepatic fibrosis and $4 / 10$ $(40 \%)$ patients could achieve regression of liver cirrhosis. ${ }^{71,108}$
Attention should be paid to reports about lactic acidosis for patients with severe hepatic diseases.

\section{Tenofovir disoproxil fumarate (TDF)}

Phase III clinical trial results indicated that the rates of undetectable HBV DNA ( $<400$ copies/mL), HBeAg seroconversion and normalization of ALT were $76 \%, 21 \%$ and $68 \%$, respectively at week 48 of TDF therapy for patients with $\mathrm{HBeAg}$-positive $\mathrm{CHB}$. On the other hand, the rates of undetectable HBV DNA ( $<400$ copies/mL) and normalization of ALT were $93 \%$ and $76 \%$ respectively at week 48 of TDF therapy for patients with $\mathrm{HBeAg}$-negative CHB. ${ }^{109}$

The rates of histological improvement and regression of fibrosis were $87 \%$ and $51 \%$ respectively for the 5-year TDF therapy. Among patients who were diagnosed with cirrhosis before treatment (Ishak score of 5 or 6 ), the Ishak score was reduced by at least 1 point in $74 \%$ of patients after treatment for 5 years. ${ }^{72}$

The rates of undetectable HBV DNA ( $<400$ copies $/ \mathrm{mL}$ ), $\mathrm{HBeAg}$ seroconversion and $\mathrm{HBsAg}$ clearance were $98 \%, 31 \%$ and $13 \%$ respectively through 8 -year TDF therapy for patients with $\mathrm{HBeAg}$-positive $\mathrm{CHB}$. On the other hand, the rate of undetectable HBV DNA ( $<400$ copies $/ \mathrm{mL}$ ) was $99.6 \%$ for patients with HBeAg-negative CHB. TDF-related resistance was not detected. During long-term treatment, $2.2 \%$ of patients presented with increase in serum creatinine level of $\geq 0.5 \mathrm{mg} / \mathrm{dL}$, and the creatinine clearance rate was $<50 \mathrm{~mL} /$ min for $1 \%$ of the patients. In addition, renal insufficiency and low-phosphorous osteopathy should be monitored for patients who receive treatment for a long-term period. ${ }^{110}$

Studies on TDF treatment for 48 weeks to 168 weeks in NA treatment-experienced patients indicated that regardless of LAM resistance, ADV resistance and ETV resistance or unsatisfactory responses to ADV or resistance to both LAM and ADV, etc., the TDF therapy demonstrated high virological responses and was associated with satisfactory tolerance. ${ }^{111-114}$

\section{Telbivudine (LdT)}

Results from a 52-week phase III clinical trial in China and a 104-week global multicenter study demonstrated that the antiviral activity of LdT was higher than that of LAM, and the incidence rate of drug resistance for LdT was lower than that of $L A M,{ }^{115,116}$ but the overall drug resistance rate was still high. For $\mathrm{HBeAg}$-positive patients with baseline HBV DNA $<10^{9}$ copies/mL and ALT $\geq 2$ ULN, or HBeAg-negative patients with HBV DNA $<10^{7}$ copies $/ \mathrm{mL}$, in the case of HBV DNA $<300$ copies/mL upon 24-week LdT therapy, better efficacy and lower drug-resistance incidence rate are obtained after treatment for $1-2$ years. ${ }^{117}$

The overall incidence rate of adverse events for LdT therapy was similar to that of LAM therapy, but the proportions of patients with grade 3 and grade 4 creatine kinase increase were $7.5 \%$ and $12.9 \%$ respectively at week 52 and week 104 of treatment, while the proportions in the LAM group were $3.1 \%$ and $4.1 \%$ respectively. ${ }^{115,116}$ Attention should be paid to rare reports about myositis, rhabdomyolysis and lactic acidosis events. LdT in combination with IFN- $\alpha$ can lead to peripheral neuropathy and shall be listed as a contraindication. 
Hou J. et al: Guideline for $\mathrm{CHB}$

$A D V$

Domestic and overseas randomized double-blind clinical trials have shown that oral ADV therapy could significantly suppress HBV DNA replication, promote the normalization of ALT and improve necroinflammatory status and fibrosis of hepatic tissues in patients with $\mathrm{HBeAg}$-positive $\mathrm{CHB}$. For patients with $\mathrm{HBeAg}$-positive $\mathrm{CHB}$, at year 1, 2, 3 and 5 of treatment, the proportions of patients with HBV DNA $<1000$ copies/mL were $28 \%, 45 \%, 56 \%$ and $58 \%$ respectively, the $\mathrm{HBeAg}$ seroconversion rates were $12 \%, 29 \%, 43 \%$ and $48 \%$ respectively, and the drug resistance rates were $0 \%, 1.6 \%, 3.1 \%$ and $20 \%$ respectively. ${ }^{118,119}$ For patients with HBeAg-negative $\mathrm{CHB}$ receiving 5 years of treatment, the proportion of patients with HBV DNA $<1000$ copies/mL was $67 \%$ and the rate of normalization of ALT was $69 \%$; the cumulative incidence rate of ADV generic resistance was $29 \%$ at year 5 of treatment. ${ }^{120}$

$A D V$ in combination with LAM therapy can effectively suppress HBV DNA for LAM-resistant patients with CHB, and the incidence rate of ADV resistance is lower for patients who receive the combination therapy. ${ }^{121}$

At year 5 of long-term ADV therapy, patients with increase in serum creatinine $>0.5 \mathrm{mg} / \mathrm{dL}$ accounted for $3 \%$, but the increase in serum creatinine was reversible. ${ }^{118,120}$ The China Federal Drug Administration has reported an alert for risk of low-phosphorous osteopathy and osteomalacia related to long-term ADV treatment. Osteomalacia is mainly featured by a series of symptoms and signs such as non-mineralized bonelike tissue hyperplasia, osteomalacia, and susceptibility to ostalgia, bone deformity and fracture. Renal insufficiency and low-phosphorous osteopathy, especially Fanconi syndrome, should be monitored for patients who receive ADV treatment for a long period.

\section{$L A M$}

Results of domestic and overseas randomized control clinical trials have indicated that LAM therapy $(100 \mathrm{mg}$ q.d. p.o.) could significantly suppress HBV DNA level. The HBeAg seroconversion rate was reportedly improved as treatment was prolonged (i.e. $16 \%, 17 \%, 23 \%, 28 \%$ and $35 \%$ respectively at year 1,2 , 3,4 and 5 of treatment). ${ }^{122}$ Randomized double-blind clinical trials have indicated that for patients with CHB accompanied by significant hepatic fibrosis and compensated liver cirrhosis, 3 years of LAM therapy could delay disease progression, reduce the incidence rate of hepatic function decompensation and HCC. ${ }^{123}$ For patients with decompensated liver cirrhosis, LAM therapy could also improve hepatic functions and extend survival time. ${ }^{124}$ However, with the extension of treatment, the incidence rate of viral drug-resistance mutation was increased (i.e. $14 \%, 38 \%, 49 \%$ and $66 \%$ respectively at year $1,2,3$ and 4 of treatment). ${ }^{122}$

\section{Efficacy prediction and therapy optimization in NA therapy}

It is emphasized that the preferred drug is the agent with high genetic barrier to resistance during NA treatment in $\mathrm{CHB}$ patients. When agents with low genetic barrier to resistance are used, therapy should be optimized in order to improve efficacy and reduce resistance. Two-year results of a prospective multicenter clinical trial, the EFFORT study, ${ }^{117}$ showed that patients with satisfactory responses in the early phase of LdT therapy (i.e. HBV DNA <300 copies / $\mathrm{mL}$ at week 24) continued to receive the monotherapy, and $88.6 \%$ of patients achieved HBV DNA <300 copies/mL through the 2-year treatment; the rates of $\mathrm{HBeAg}$ seroconversion and drug resistance were $41.3 \%$ and $5.5 \%$ respectively. For patients with unsatisfactory responses in the early phase of LdT therapy (i.e. HBV DNA $\geq 300$ copies/mL at week 24), ADV was added to optimize treatment; the proportion of patients with HBV DNA $<300$ copies/mL through the 2-year treatment was $71.1 \%$, and the incidence rate of drug resistance was $0.5 \%$. When the optimized therapy was applied, the proportion of patients with HBV DNA <300 copies/mL was $76.7 \%$ among all subjects, and the drug resistance rate was $2.7 \%$. It has been shown by data of domestic and overseas studies that optimized therapy can improve the efficacy and reduce drug resistance, but the overall incidence rate of drug resistance is still higher than that of ETV and TDF therapies (non-head-to-head comparison).

\section{Monitoring during NA therapy}

Baseline detection of related indicators before treatment: (1) Hepatic biochemical indicators, mainly including ALT, AST, bilirubin and albumin, etc. ; (2) Virological and serological markers, mainly including HBV DNA, HBsAg, HBeAg and anti-HBe; (3) According to patients' conditions, routine blood examination, serum creatinine and creatine kinase are detected, with blood phosphorus and lactic acid detected if necessary; (4) Noninvasive assessment of liver fibrosis (e.g., liver stiffness measurement); (5) If allowable, liver biopsy is considered before and after treatment.

Pay close attention to compliance problems with the therapy. These problems include dosage, usage, missing doses, whether drugs are discontinued or intervals between two doses are prolonged without physicians' instruction; make sure that patients know the risks associated with arbitrary drug discontinuation and seek to improve patient compliance.

Prevention and treatment of infrequent and rare adverse events. The overall safety and tolerance of NAs are satisfactory, but there are still infrequent and rare severe adverse events in clinical application; for example, renal insufficiency (mainly seen in ADV therapy), low-phosphorous osteopathy (mainly seen in ADV and TDF therapy), myositis (mainly seen in LdT therapy), rhabdomyolysis (mainly seen in LdT therapy) and lactic acidosis (seen in LAM, ETV and LdT) etc., to which attention should be paid. It is advised to take a complete history of related diseases in order to reduce risks. Close observation should be made for patients with significant elevation in serum creatinine, creatine kinase or lactic dehydrogenase accompanied by corresponding clinical manifestations, such as poor general physical conditions, significant myalgia and myasthenia. Once patients are diagnosed with uremia, myositis, rhabdomyolysis or lactic acidosis, etc., drugs should be immediately discontinued or replaced by other drugs, and active and corresponding treatment intervention should be implemented.

Drug resistance monitoring. Drug resistance is one of main problems of long-term NA therapy in patients with $\mathrm{CHB}$. Drug resistance can induce virological breakthrough, biochemical breakthrough, virological rebound and flare of hepatitis, and some patients may experience liver decompensation, acute liver failure and even death. ${ }^{137}$ 


\section{Prevention and management of NA resistance}

Whether antiviral therapy is required or not should be strictly evaluated. Antiviral therapy is not applicable to patients with mild inflammatory lesions in the liver and who are difficult to obtain sustained responses (e.g., immune tolerance phase with normal ALT and positivity for HBeAg), especially when such patients are under the age of 30 .

Selection of NAs. ETV and TDF are preferentially recommended for treatment-naïve patients.

HBV DNA level should be detected regularly during the treatment to find primary nonresponse or virological breakthrough in a timely manner. Once virological breakthrough occurs, detection of drug resistance for all genotypes should be implemented and rescue therapy should be given as soon as possible (for details, refer to Table 6 ). The response rate is low for patients with resistance to NAs who switch to peg-IFN- $\alpha$ therapy ${ }^{138}$ (IIA).

Recommendations for antiviral therapy and follow-up management

\section{Recommendations for antiviral therapy for patients with HBeAg-positive CHB}

In the natural history of HBV infections, spontaneous HBeAg seroconversion arises in patients with $\mathrm{HBeAg}$-positive $\mathrm{CHB}$ and ALT elevation as intrahepatic inflammatory activity in remission during the follow-up, and ALT level returns to the normal value. ${ }^{139}$ Therefore, it is advised for patients with $\mathrm{HBeAg}$-positive $\mathrm{CHB}$ and ALT elevation to be observed for 3-6 months. In case of no spontaneous $\mathrm{HBeAg}$ seroconversion but continuously elevated ALT, the antiviral therapy should be considered. ${ }^{140}$

\section{Drug selection}

Recommendation 5: Entecavir, TDF or peg-IFN is preferred for treatment-naïve patients (A1). For patients who have received LAM and/or LdT, in case of HBV DNA >300 copies/ $\mathrm{mL}$ at week 24 of treatment, it is advised to switch to TDF or add on ADV therapy; for patients treated with ADV, in case of viral reduction $<2 \log _{10} \mathrm{IU} / \mathrm{mL}$ at week 24 of treatment compared with baseline level, it is advised to switch to ETV or $\mathrm{TDF}^{117,141}$ (A1).

\section{Recommended treatment duration}

Recommendation 6: For NA treatment, the recommended total duration is at least 4 years. After at least 3 years of consolidation therapy (follow-up every 6 months) with no clinical changes, treatment might be stopped if patients achieve undetectable HBV DNA, ALT normalization and
HBeAg seroconversion, but extension of treatment duration can reduce relapse ${ }^{142-145}$ (B1).

Recommendation 7: The current recommended duration of IFN- $\alpha$ and peg-IFN- $\alpha$ treatment is 1 year. If HBsAg quantification is still $>20000 \mathrm{IU} / \mathrm{mL}$ through 24 weeks of therapy, it is advised to stop this therapy ${ }^{101}$ (B1).

\section{Recommendations for antiviral therapy for patients with HBeAg-negative CHB}

The specific duration of treatment is unclear for patients with $\mathrm{HBeAg}$-negative $\mathrm{CHB}$ and the relapse rate is high after drugs are discontinued, so the course of treatment should be long. ${ }^{147}$

\section{Drug selection}

Recommendation 8: It is preferably recommended for treatment-naïve patients to select ETV, TDF or peg-IFN (A1). For patients who have received LAM and/or LdT, in case of HBV DNA $>300$ copies/mL at week 24 of treatment, a switch to TDF or addition of ADV therapy is indicated; for patients treated with $A D V$, in case of viral reduction $<2 \log _{10} \mathrm{IU} / \mathrm{mL}$ at week 24 of treatment compared with baseline level, a switch to ETV or TDF is indicated (A1).

\section{Recommended course of treatment}

Recommendation 9: After at least 1.5 years of consolidation therapy (follow-up for at least three times with the interval of 6 months) with no clinical changes, treatment might be stopped if HBsAg loss and undetectable HBV DNA is achieved by NA therapy ${ }^{143,147}$ (B1).

Recommendation 10: The current recommended duration of IFN- $\alpha$ and peg-IFN- $\alpha$ treatment is 1 year. In case no decrease is found in HBsAg quantitation through therapy for 12 weeks and decline of HBV DNA level from baseline $<2 \log _{10}$ is observed, it is advised to stop IFN- $\alpha^{103}$ and switch to NA therapy (B1).

\section{Patients with Compensated and Decompensated Cirrhosis of Hepatitis B}

Long-term antiviral therapy is required for patients who have developed liver cirrhosis.

Drug selection

Recommendation 11: It is preferably recommended for treatment-naïve patients to select ETV or TDF (A1). IFN- $\alpha$ may induce liver failure and other complications, making IFN- $\alpha$ forbidden for patients with decompensated cirrhosis and applied with caution for patients with compensated cirrhosis ${ }^{148}(\mathrm{~A} 1)$.

Table 6. Recommendations of rescue therapy for NA resistance

\begin{tabular}{ll}
\hline Types of drug resistance & Recommended drugs \\
\hline LAM or LdT resistance & Switch to TDF or ADV added \\
ADV resistance, LAM not applied previously & Switch to ETV or TDF \\
ADV resistance arises while treating LAM/LdT resistance & Switch to TDF or ETV+ADV \\
ETV resistance & Switch to TDF or ADV added \\
Multi-drug resistance mutation (A181T+N236T+M204V) & TDF, ETV in combination with TDF or ETV+ADV \\
\hline
\end{tabular}


Hou J. et al: Guideline for $\mathrm{CHB}$

Table 7. Monitoring during antiviral therapy. The aim of regular monitoring during antiviral therapy is to evaluate the effectiveness, treatment adherence, drug resistance and side effects.

\begin{tabular}{|c|c|c|}
\hline $\begin{array}{l}\text { Monitoring } \\
\text { tests }\end{array}$ & $\begin{array}{l}\text { Recommended frequency for } \\
\text { patients receiving IFN therapy }\end{array}$ & $\begin{array}{l}\text { Recommended frequency for } \\
\text { patients receiving NA therapy }\end{array}$ \\
\hline $\begin{array}{l}\text { Complete } \\
\text { blood count }\end{array}$ & $\begin{array}{l}\text { Every } 1-2 \text { weeks in the first month of treatment, and then } \\
\text { monthly till the end of the treatment }\end{array}$ & Every 6 months till the end of treatment \\
\hline $\begin{array}{l}\text { Biochemical } \\
\text { tests }\end{array}$ & Every month till the end of treatment & Every 3-6 months till the end of treatment \\
\hline HBV DNA & Every 3 months till the end of treatment & Every 3-6 months till the end of treatment \\
\hline $\begin{array}{l}\mathrm{HBsAg} / \mathrm{HBsAb} / \\
\mathrm{HBeAg} / \mathrm{HBeAb}\end{array}$ & Every 3 months & Every 6 months till the end of treatment \\
\hline AFP & Every 6 months & Every 6 months till the end of treatment \\
\hline LSM & Every 6 months & Every 6 months till the end of treatment \\
\hline $\begin{array}{l}\text { Thyroid } \\
\text { function and } \\
\text { blood glucose }\end{array}$ & $\begin{array}{l}\text { Every } 3 \text { months. For the patients with abnormal thyroid } \\
\text { function or diabetes mellitus before treatment, thyroid } \\
\text { function or blood sugar should be monitored monthly. }\end{array}$ & According to previous history \\
\hline Mental status & $\begin{array}{l}\text { Evaluate the mental status closely and regularly. For the } \\
\text { patients with severe depression and suicidal tendency, } \\
\text { discontinue the treatment immediately. }\end{array}$ & According to previous history \\
\hline Abdominal US & $\begin{array}{l}\text { Every } 6 \text { months. For the patients with cirrhosis, monitor every } \\
3 \text { months. Consider CT or MRI if abnormalities show on US. }\end{array}$ & Every 6 months till the end of treatment \\
\hline Other tests & According to the individual patient situation & $\begin{array}{l}\text { For patients receiving LdT, creatine kinase } \\
\text { should be monitored every 3-6 months. For } \\
\text { patients who are receiving TDF or ADV, serum } \\
\text { creatinine and serum phosphate should be } \\
\text { monitored every } 3-6 \text { months. }\end{array}$ \\
\hline
\end{tabular}

Patient follow-up management

\section{Follow-up for chronic HBV carriers and inactive HBsAg carriers}

During the immune-tolerant period, liver biopsy often reveals absence or mild inflammation, and the response to antiviral therapy is unsatisfactory; thus, antiviral therapy is not recommended. ${ }^{140}$ However, antiviral therapy should be considered for those aged $>35$ years with high viral load and family history of HCC. With increasing age, some immune-tolerant patients may transit to immune-active phase and experience hepatitis activation. ${ }^{46}$ Therefore, complete blood count, biochemical tests, virological markers, AFP, ultrasonography and noninvasive fibrosis tests should be monitored every 3-6 months for chronic HBV carriers, and liver biopsy should be considered if necessary. Antiviral therapy should be initiated immediately if the patients meet the treatment indications.

Antiviral therapy is not recommended for inactive $\mathrm{HBsAg}$ carriers, but those patients have potential to develop HBeAgnegative $\mathrm{CHB}$ and $\mathrm{HCC}$ and should be subject to long-term follow-up. ${ }^{149}$ Therefore, complete blood count, biochemical tests, virological markers, AFP, ultrasonography and noninvasive fibrosis tests should be monitored every 6 months. Antiviral therapy should start immediately if the patients meet the treatment indications.

\section{Patient follow-up during the antiviral therapy (Table 7)}

Regular follow-up during the antiviral therapy aims to monitor clinical efficacy, patient compliance, drug resistance and adverse events.

\section{Follow-up after treatment discontinuation}

The aim of monitoring after treatment is to evaluate the longterm effectiveness of antiviral therapy, progression of liver disease and development of HCC. Regardless of the patients having achieved treatment response or not, liver function, HBV serological markers and HBV DNA level should be monitored monthly within 3 months post-treatment, and then every 3 months for at least 1 year thereafter to identify hepatitis reactivation early. Afterwards, the patients with continuously normal ALT and undetectable HBV DNA, are suggested to undergo monitoring of HBV DNA, liver function, AFP and ultrasonography at least once a year. The patients with normal ALT and detectable HBV DNA are suggested to undergo monitoring of HBV DNA, ALT, AFP and ultrasonography every 6 months. For patients with cirrhosis, AFP and abdominal ultrasonography should be monitored every 3 months for HCC screening, and CT or MRI is suggested if necessary. Cirrhotic patients are required to undergo gastroscopy every 1-2 years to evaluate the progression of esophageal and gastric varices.

\section{Treatment recommendations in special populations}

\section{Patients with nonresponse and suboptimal response}

Patients with nonresponse to conventional IFN- $\alpha$ or peg-IFN- $\alpha$ therapy are recommended to switch to NA retreatment (A1). In settings with good treatment adherence, the primary nonresponders or suboptimal responders to NAs with low barrier to resistance are recommended to adjust the regimen and continue treatment. ${ }^{117,141}$ (A1). For the patients with primary nonresponse or suboptimal response to ETV or TDF, it is 
Hou J. et al: Guideline for CHB

controversial whether the treatment regimen should be adjusted or not. ${ }^{150}$

\section{Patients undergoing chemotherapy or immunosuppressive therapy}

Reactivation of HBV replication with hepatitis flare has been reported in $20 \%-50 \%$ of patients with chronic HBV infection undergoing cancer chemotherapy or immunosuppressive therapy, and severe cases may progress to acute liver failure and even death. High viral load at baseline is the most important risk factor for HBV reactivation. ${ }^{151}$ Prophylactic antiviral therapy can significantly reduce the reactivation of hepatitis B. ${ }^{152}$ Furthermore, due to high efficacy and low drug resistance, ETV or TDF is recommended for those patients. ${ }^{153}$

HBsAg, anti-HBc and HBV DNA tests are recommended before chemotherapy and immunosuppression to evaluate the risk of HBV reactivation. Antiviral therapy should be initiated 1 week prior to immunosuppression and chemotherapy. For patients with HBsAg-negative and anti-HBc-positive status, prophylactic antiviral treatment can be considered before anti-CD20 monoclonal antibody therapy ${ }^{154,155}$ (A1). Antiviral therapy is recommended to continue for at least 6 months after cession of chemotherapy and immunosuppression. HBV reactivation and disease aggravation may occur after the discontinuation of NA therapy; therefore, regular followup and monitoring are required (A1).

\section{Coinfection with HBV and HCV}

The therapeutic strategy for HBV and HCV coinfection should be designed according to HBV DNA, HCV RNA and ALT levels. For patients with undetectable HBV DNA and detectable HCV RNA, the anti-HCV therapy regimen is recommended but prevention of HCV reactivation should be considered (A1). If both HBV DNA and HCV RNA are detectable, the standard dose of peg-IFN- $\alpha$ and ribavirin regimen for 3 months is suggested. For patients who failed to achieve a $>2 \log _{10} \mathrm{IU} /$ $\mathrm{mL}$ decline in serum HBV DNA levels, it is recommended to add ETV or TDF, or switch to the combination of anti-HCV direct-acting antiviral and ETV/TDF therapy ${ }^{9,56,156-158}$ (A1).

\section{Coinfection with HBV and HIV}

For the patients who are not receiving antiretroviral therapy (ART) temporarily (CD4+ T lymphocyte count $>500 / \mu \mathrm{L})$, pegIFN- $\boldsymbol{\alpha}$ or ADV are recommended if they meet the criteria of anti-HBV therapy (C1). Liver biopsy or noninvasive fibrosis tests are suggested for patients with transient or mild ALT elevation (1 2 $\times$ ULN) (B2).

If CD4+ T lymphocyte count is $\leq 500 / \mu L$, ART should be initiated regardless of chronic hepatitis $B$ infection phase, and TDF plus LAM therapy or TDF plus emtricitabine (FTC) are preferred ${ }^{2,159-161}$ (A1). For patients who are receiving and respond to ART, NAs or peg-IFN- $\alpha$ could be administered if there is no anti-HBV drug included in the ART regimen (C2).

When the ART regimen is required to be adjusted, the patients should continue the current anti-HBV drugs or switch to alternative drugs with anti-HBV activity, unless they complete sufficient consolidation treatment after $\mathrm{HBeAg}$ seroconversion (B1).

\section{Liver failure caused by hepatitis B}

HBsAg-positive or HBV DNA-positive patients with acute and subacute liver failure should initiate NA antiviral therapy as soon as possible, and ETV or TDF therapy is preferred. The antiviral therapy should be continued until HBsAg seroconversion is achieved (C1). For patients with acute/subacute-onchronic liver failure and chronic liver failure, antiviral therapy should be initiated if HBV DNA positivity is present. ${ }^{3,162-166}$ Monitoring of serum lactic acid levels is crucial for patients with liver failure during antiviral treatment (C1).

\section{HBV-related HCC}

For patients with HBV related HCC, HBV reactivation may be triggered by surgical excision, hepatic arterial chemoembolization, radiotherapy or ablation and other treatments. It is generally reported that HBV viral load at the time of resection is associated with postoperative recurrence independently, and antiviral therapy could significantly improve recurrencefree survival and overall survival. ${ }^{167,168}$ Therefore, HBV DNApositive patients with $\mathrm{HCC}$ are recommended to initiate NA treatment, and ETV or TDF is preferred (A1).

\section{Patients with liver transplantation (LT)}

For CHB patients who need LT, NAs with high potency and low drug resistance are recommended. Antiviral therapy before LT may prevent HBV recurrence after LT by reducing the level of viremia to extremely low levels. For low risk of HBV graft recurrence patients (i.e. with undetectable HBV DNA levels at the time of transplant), ETV or TDF should be administered before LT and HBIG is not required after $\mathrm{LT}^{169}$ (B1). For high risk of HBV graft recurrence patients, HBIG should be administered in the anhepatia phase. The regimen of low-dose HBIG plus NAs is recommended after the LT, and ETV or TDF combination with low-dose HBIG could reduce recurrence more significantly ${ }^{169-171}$ (A1). For patients who have initiated other NAs, it is recommended to monitor drug resistance closely, and adjust treatment regimen accordingly. A lifelong prophylactic therapy is suggested to prevent hepatitis $B$ reactivation after the $L^{172}(A 1)$.

\section{HBV and pregnancy}

For female patients of childbearing age, IFN or NA treatment should be initiated before pregnancy if antiviral therapy is indicated, in order to complete antiviral treatment 6 months prior to pregnancy. Reliable contraception is suggested during the treatment period (A1). For pregnant females with chronic HBV infection, when serum ALT levels elevate mildly, the patients should be monitored closely. If liver disease has severely progressed, TDF or LdT could be administered after the risks and benefits of the treatment plan have been fully discussed with the patient (A1).

If female patients have an unexpected pregnancy during IFN- $\alpha$ treatment, the pregnancy should be terminated (B2). If unexpected pregnancy occurs during treatment with Category B drugs (i.e. LdT and TDF) or LAM, the treatment could be continued after the risks and benefits of the treatment plan have been fully discussed with the patient. If females have an unexpected pregnancy during ETV or ADV treatment, the patient should be switched to TDF or LdT to continue the pregnancy after full discussion of the related risks and benefits ${ }^{173,174}(A 1)$. 
Pregnant patients in the immune tolerance phase often have high serum HBV DNA load, which is an independent risk factor of mother-to-Child transmission. Hepatitis $B$ vaccination for infants and maternal antiviral treatment could significantly reduce the incidence of mother-to-infant transmission. If HBV DNA $>2 \times 10^{6} \mathrm{IU} / \mathrm{mL}$ is found in the second and third trimester, TDF, LdT or LAM could be administered from 24-28 weeks of gestation after full discussion is made and with informed consent (A1). It is recommended to stop antiviral treatment after delivery, and breastfeeding is discouraged during maternal NA treatment ${ }^{16,175-177}(\mathrm{C} 2)$.

Male fertility issues during antiviral therapy exist. For male patients receiving IFN- $\alpha$ treatment, reliable contraception is suggested until 6 months after treatment. Due to lack of sufficient evidence for adverse impact of NA therapy on sperm, male patients receiving NA treatment could consider child-bearing after full discussion (C2).

\section{Pediatric patients}

Since pediatric patients with HBV infection are often in the immune tolerant phase, antiviral therapy is generally not recommended. For pediatric patients with advanced liver disease or liver cirrhosis, antiviral therapy should be initiated immediately; however, safety and drug resistance problems for long-term treatment should also be considered. The US Food and Drug Administration approved 5 medications for treatment of children with CHB: IFN- $\alpha$ (2 17 years), LAM ( $2 \sim 17$ years), ADV (12 17 years), ETV ( $2 \sim 17$ years), and TDF (12 17 years).

Clinical trials have indicated that the efficacy of conventional IFN- $\alpha$ in pediatric patients is similar to that in adult patients. The recommended regimen of IFN- $\alpha$ for pediatric patients is $3 \sim 6$ million $\mathrm{U} / \mathrm{m}^{2}$, three times weekly, and the maximum dose should not exceed 10 million $\mathrm{U} / \mathrm{m}^{2}$. However, IFN- $\alpha$ is contraindicated in patients under 12 months-old. On the basis of fully informed consent, patients at the age of $2 \sim 11$ years-old could receive ETV, and patients at the age of 12 17 years-old could receive ETV or TDF (A1). The dose of antiviral drugs for pediatric patients is recommended by the US Food and Drug Administration and WHO (Table 8). ${ }^{9,178-180}$

\section{Patients with renal injury}

Antiviral therapy is crucial for HBV-related glomerulonephritis treatment. NAs with high potency and low drug resistance are recommended. NAs are excreted by kidney and should be dose adjusted based on creatinine clearance rates, according to

Table 8. Recommended dose of NAs for pediatric patients

\begin{tabular}{lll}
\hline Drug & Weight, Kg & Doses, mg/d \\
\hline ETV, age $\geq 2$ years & $10 \sim 11$ & 0.15 \\
& $>11 \sim 14$ & 0.20 \\
& $>14 \sim 17$ & 0.25 \\
& $>17 \sim 20$ & 0.30 \\
& $>20 \sim 23$ & 0.35 \\
& $>23 \sim 26$ & 0.40 \\
& $>26 \sim 30$ & 0.45 \\
TDF, age $\geq 12$ years & $>30$ & 0.5 \\
\hline
\end{tabular}

relevant drug instructions. ADV or TDF should be avoided in CHB patients with renal diseases or at high risk of renal diseases. It has been shown that LdT may improve the estimated glomerular filtration rate, but the mechanism of such is unclear. LdT and ETV are the preferred options for CHB patients with risks of renal disease ${ }^{9,178-180}$ (B1).

\section{Recommendations}

Recommendation 12: Patients with nonresponse to standard regimen conventional IFN- $\alpha$ or peg-IFN- $\alpha$, could switch to NA treatment. In settings with good treatment adherence, primary nonresponders or suboptimal responders to NAs with low barrier to resistance are recommended to adjust the regimen and continue treatment (A1).

Recommendation 13: $\mathrm{HBsAg}$, anti-HBc and HBV DNA tests are recommended before chemotherapy and immunosuppression to evaluate the risk of HBV reactivation. Antiviral therapy should be initiated 1 week prior to immunosuppression and chemotherapy. ETV and TDF are the preferred options. For patients with HBsAg-negative and anti-HBc-positive status, prophylactic antiviral treatment can be considered before anti-CD20 monoclonal antibody therapy (A1).

Recommendation 14: If CD4+ T lymphocyte count is $\leq 500 / \mu \mathrm{L}, \mathrm{ART}$ should be initiated regardless of CHB infection phase, and the regimens including TDF plus LAM or TDF plus FTC are preferred (A1).

Recommendation 15: HBsAg-positive or HBV DNApositive patients with acute and subacute liver failure should initiate NA antiviral therapy as soon as possible, and ETV or TDF therapy is preferred (A1).

Recommendation 16: HBV DNA-positive patients with HCC are recommended to initiate NA treatment, and ETV or TDF is preferred (A1).

Recommendation 17: For patients with undetectable HBV DNA levels before transplantation, who are at low risk of HBV graft recurrence, ETV or TDF should be administered before LT and HBIG is not required after LT (B1). For patients with high risk of HBV graft recurrence, the regimen of low-dose HBIG combination with NAs is recommended, and ETV or TDF combination with low-dose HBIG could reduce recurrence more significantly (A1).

Recommendation 18: For pregnant females with hepatitis flares, if serum ALT levels elevate mildly, the patients should be monitored closely. If liver disease has severely progressed, TDF or LdT could be administered after the risks and benefits of the treatment plan have been fully discussed with the patient $(A 1)$.

Recommendation 19: If female patients have an unexpected pregnancy during IFN- $\alpha$ treatment, the pregnancy should be terminated (B2). If an unexpected pregnancy occurs during treatment with Category B drugs (LdT and TDF) or LAM, the treatment could be continued. If an unexpected pregnancy occurs during ETV or ADV treatment, the patient should be switched to TDF or LdT to continue the pregnancy (A1), and breastfeeding is discouraged during the maternal NA treatment.

Recommendation 20: In order to further reduce the possibility of HBV mother-to-infant transmission, for the patients with HBV DNA $>2 \times 10^{6} \mathrm{IU} / \mathrm{mL}$ in the second and third trimester, TDF, LdT or LAM could be administered from 24-28 weeks of gestation after full discussion is made and informed consent is obtained. It is recommended to stop antiviral treatment after delivery (B1).

Recommendation 21: For pediatric patients with advanced liver disease or liver cirrhosis, the antiviral therapy should be 
initiated immediately. IFN- $\alpha$ can be used in children older than 12 months of age. ETV can be used at 2 years and older, and TDF can be used in children aged 12 years and older (A1).

Recommendation 22: ADV or TDF should be avoided in $\mathrm{CHB}$ patients with renal diseases or high risks of renal diseases. LdT and ETV are the preferred options for CHB patients with risk of renal injury (B1).

\section{Areas of unmet need and future research}

1. Role of biological markers in the natural history of hepatitis $B$, treatment indications, efficacy prediction and prognosis evaluation;

2. Role of non-invasive fibrosis detection methods in treatment indications, efficacy evaluation and long-term follow-up;

3. Efficacy assessment and cost-effectiveness analysis of NAs and IFN- $\alpha$ combination/sequential therapy;

4. Identification of clinical standards and biological markers to predict successful NA discontinuation;

5. Impact of long-term NA therapy on cirrhosis reversion and HCC incidence;

6. Safety of long-term NA therapy and the influence of NA therapy during pregnancy on long-term safety of mothers and infants;

7. Clinical effectiveness assessment based on long-term follow-up cohorts and large data sets;

8. Exploration and development of a new type of doctorpatient interactive chronic disease management mode to reinforce patient compliance;

9. Implementation of health economics studies, and exploration of effective ways to lower the price of drugs and improve accessibility to treatment;

10. Exploration of novel therapies to eliminate HBsAg (functional cure) and evaluate long-term clinical outcomes after HBsAg clearance.

\section{Conflict of interest}

The authors have no conflict of interests related to this publication.

\section{References}

[1] Ott J], Stevens GA, Groeger J, Wiersma ST. Global epidemiology of hepatitis B virus infection: new estimates of age-specific $\mathrm{HBsAg}$ seroprevalence and endemicity. Vaccine 2012;30:2212-2219. doi: 10.1016/j.vaccine.2011.12.116.

[2] Lozano R, Naghavi M, Foreman K, Lim S, Shibuya K, Aboyans V, et al. Global and regional mortality from 235 causes of death for 20 age groups in 1990 and 2010: a systematic analysis for the Global Burden of Disease Study 2010. Lancet 2012;380:2095-2128. doi: 10.1016/S0140-6736(12)61728-0.

[3] Goldstein ST, Zhou F, Hadler SC, Bell BP, Mast EE, Margolis HS. A mathematical model to estimate global hepatitis $B$ disease burden and vaccination impact. Int J Epidemiol 2005;34:1329-1339. doi: 10.1093/ije/dyi206.

[4] Wang FS, Fan JG, Zhang Z, Gao B, Wang HY. The global burden of liver disease: the major impact of China. Hepatology 2014;60:2099-2108. doi: 10.1002/hep.27406.

[5] Fung J, Seto WK, Lai CL, Yuen J, Wong DK, Yuen MF. Profiles of HBV DNA in a large population of Chinese patients with chronic hepatitis $B$ : implications for antiviral therapy. J Hepatol 2011;54:195-200. doi: 10.1016/j.jhep. 2010.06.031.

[6] Liang X, Bi S, Yang W, Wang L, Cui G, Cui F, et al. Epidemiological serosurvey of hepatitis $B$ in China-declining HBV prevalence due to hepatitis $B$ vaccination. Vaccine 2009;27:6550-6657. doi: 10.1016/j.vaccine.2009.08.048.

[7] Liang X, Bi S, Yang W, Wang L, Cui G, Cui F, et al. Evaluation of the impact of hepatitis B vaccination among children born during 1992-2005 in China. J Infect Dis 2009;200:39-47. doi: 10.1086/599332.

[8] Lu FM, Zhuang H. Management of hepatitis B in China. Chin Med J (Engl) $2009 ; 122: 3-4$.
[9] WHO Guidelines Approved by the Guidelines Review Committee. Guidelines for the Prevention, Care and Treatment of Persons with Chronic Hepatitis B Infection. Geneva: World Health Organization 2015.

[10] Mast EE, Margolis HS, Fiore AE, Brink EW, Goldstein ST, Wang SA, et al. A comprehensive immunization strategy to eliminate transmission of hepatitis B virus infection in the United States: recommendations of the Advisory Committee on Immunization Practices (ACIP) part 1: immunization of infants, children, and adolescents. MMWR Recomm Rep 2005;54:1-31.

[11] Chinese Center for Disease Control and Prevention. Management of hepatitis $B$ vaccine for children in China, 2002. Beijing, China.

[12] Xia GL, Gong J, Wang J], Meng ZD, Jia ZY, Cao HL, et al. Efficacy of recombinant hepatitis $B$ vaccine and low-dose hepatitis $B$ immune globulin in preventing mother-infant transmission of hepatitis $B$ virus infection. Zhonghua Liu Xing Bing Xue Za Zhi 2003;24:362-365.

[13] Singh AE, Plitt SS, Osiowy C, Surynicz K, Kouadjo E, Preiksaitis J, et al. Factors associated with vaccine failure and vertical transmission of hepatitis B among a cohort of Canadian mothers and infants. J Viral Hepat 2011;18: 468-473. doi: 10.1111/j.1365-2893.2010.01333.x.

[14] Tran TT. Management of hepatitis B in pregnancy: weighing the options. Cleve Clin J Med 2009;76 Suppl 3:S25-S29. doi: 10.3949/ccjm.76.s3.06.

[15] Han L, Zhang HW, Xie JX, Zhang Q, Wang HY, Cao GW. A meta-analysis of lamivudine for interruption of mother-to-child transmission of hepatitis $B$ virus. World J Gastroenterol 2011;17:4321-4333. doi: 10.3748/wjg.v17.i38.4321.

[16] Han GR, Cao MK, Zhao W, Jiang HX, Wang CM, Bai SF, et al. A prospective and open-label study for the efficacy and safety of telbivudine in pregnancy for the prevention of perinatal transmission of hepatitis B virus infection. J Hepatol 2011;55:1215-1221. doi: 10.1016/j.jhep.2011.02.032.

[17] Pan CQ, Mi LJ, Bunchorntavakul C, Karsdon J, Huang WM, Singhvi G, et al. Tenofovir disoproxil fumarate for prevention of vertical transmission of hepatitis $B$ virus infection by highly viremic pregnant women: a case series. Dig Dis Sci 2012:57:2423-2429. doi: 10.1007/s10620-012-2187-3.

[18] Zanetti AR, Mariano A, Romanò L, D'Amelio R, Chironna M, Coppola RC, et al. Long-term immunogenicity of hepatitis $B$ vaccination and policy for booster: an Italian multicentre study. Lancet 2005;366:1379-1384. doi: 10.1016/S0140-6736(05)67568-X.

[19] U.S. Public Health Service. Updated U.S. public health service guidelines for the management of occupational exposures to HBV,. HCV, and HIV and recommendations for postexposure prophylaxis. MMWR Recomm Rep 2001;50:1-52.

[20] Yan H, Zhong G, Xu G, He W, Jing Z, Gao Z, et al. Sodium taurocholate cotransporting polypeptide is a functional receptor for human hepatitis $B$ and D virus. Elife 2012;1:e00049. doi: 10.7554/eLife.00049.

[21] Liu C], Kao JH. Global perspective on the natural history of chronic hepatitis B: role of hepatitis B virus genotypes A to J. Semin Liver Dis 2013;33:97102. doi: $10.1055 / \mathrm{s}-0033-1345716$.

[22] Lin $\mathrm{CL}, \mathrm{Kao} \mathrm{JH}$. The clinical implications of hepatitis $B$ virus genotype: Recent advances. J Gastroenterol Hepatol 2011;26 Suppl 1:123-130. doi: 10.1111/j.1440-1746.2010.06541.x.

[23] Livingston SE, Simonetti JP, Bulkow LR, Homan CE, Snowball MM, Cagle HH, et al. Clearance of hepatitis $B$ e antigen in patients with chronic hepatitis $B$ and genotypes A, B, C, D, and F. Gastroenterology 2007;133:1452-1457. doi: 10.1053/j.gastro.2007.08.010.

[24] Yu MW, Yeh SH, Chen PJ, Liaw YF, Lin CL, Liu CJ, et al. Hepatitis B virus genotype and DNA level and hepatocellular carcinoma: a prospective study in men. J Natl Cancer Inst 2005;97:265-272. doi: 10.1093/jnci/dji043.

[25] Lim SG, Cheng Y, Guindon S, Seet BL, Lee LY, Hu P, et al. Viral quasi-species evolution during hepatitis Be antigen seroconversion. Gastroenterology 2007; 133:951-958. doi: 10.1053/j.gastro.2007.06.011.

[26] Wang HY, Chien MH, Huang HP, Chang HC, Wu CC, Chen PJ, et al. Distinct hepatitis $B$ virus dynamics in the immunotolerant and early immunoclearance phases. J Virol 2010;84:3454-3463. doi: 10.1128/JVI.02164-09.

[27] Liu F, Chen L, Yu DM, Deng L, Chen R, Jiang Y, et al. Evolutionary patterns of hepatitis $B$ virus quasispecies under different selective pressures: correlation with antiviral efficacy. Gut 2011;60:1269-1277. doi: 10.1136/gut. 2010.226225.

[28] Lai CL, Ratziu V, Yuen MF, Poynard T. Viral hepatitis B. Lancet 2003;362: 2089-2094. doi: 10.1016/S0140-6736(03)15108-2.

[29] Liaw YF. Natural history of chronic hepatitis B virus infection and long-term outcome under treatment. Liver Int 2009;29 Suppl 1:100-107. doi: 10. 1111/j.1478-3231.2008.01941.x.

[30] Hui CK, Leung N, Yuen ST, Zhang HY, Leung KW, Lu L, et al. Natural history and disease progression in Chinese chronic hepatitis $\mathrm{B}$ patients in immunetolerant phase. Hepatology 2007;46:395-401. doi: 10.1002/hep.21724.

[31] McMahon BJ. The natural history of chronic hepatitis B virus infection. Hepatology 2009;49:S45-S55. doi: 10.1002/hep.22898.

[32] Liaw YF. Hepatitis flares and hepatitis B e antigen seroconversion: implication in anti-hepatitis B virus therapy. J Gastroenterol Hepatol 2003;18:246252. doi: $10.1046 / j .1440-1746.2003 .02976 . x$

[33] Chu CM, Hung SJ, Lin J, Tai DI, Liaw YF. Natural history of hepatitis B e antigen to antibody seroconversion in patients with normal serum 
aminotransferase levels. Am J Med 2004;116:829-834. doi: 10.1016/j. amjmed.2003.12.040.

[34] Chu CM, Liaw YF. Prevalence of and risk factors for hepatitis B viremia after spontaneous hepatitis B surface antigen seroclearance in hepatitis B carriers. Clin Infect Dis 2012;54:88-90. doi: 10.1093/cid/cir755.

[35] Chu CM, Liaw YF. Hepatitis B surface antigen seroclearance during chronic HBV infection. Antivir Ther 2010;15:133-143. doi: 10.3851/IMP1497.

[36] Fattovich G, Bortolotti F, Donato F. Natural history of chronic hepatitis B: special emphasis on disease progression and prognostic factors. J Hepatol 2008;48:335-352. doi: 10.1016/j.jhep.2007.11.011.

[37] Chen YC, Chu CM, Liaw YF. Age-specific prognosis following spontaneous hepatitis $B$ e antigen seroconversion in chronic hepatitis B. Hepatology 2010;51:435-444. doi: 10.1002/hep.23348.

[38] Park BK, Park YN, Ahn SH, Lee KS, Chon CY, Moon YM, et al. Long-term outcome of chronic hepatitis B based on histological grade and stage. J Gastroenterol Hepatol 2007;22:383-388. doi: 10.1111/j.1440-1746. 2007.04857.x.

[39] Lin SM, Yu ML, Lee CM, Chien RN, Sheen IS, Chu CM, et al. Interferon therapy in $\mathrm{HBeAg}$ positive chronic hepatitis reduces progression to cirrhosis and hepatocellular carcinoma. J Hepatol 2007;46:45-52. doi: 10.1016/j. jhep.2006.08.021.

[40] Yim HJ, Lok AS. Natural history of chronic hepatitis B virus infection: what we knew in 1981 and what we know in 2005. Hepatology 2006;43:S173S181. doi: 10.1002/hep.20956.

[41] Chu CM, Liaw YF. Hepatitis B virus-related cirrhosis: natural history and treatment. Semin Liver Dis 2006;26:142-152. doi: 10.1055/s-2006-939752.

[42] Chen YC, Chu CM, Yeh CT, Liaw YF. Natural course following the onset of cirrhosis in patients with chronic hepatitis B: a long-term follow-up study. Hepatol Int 2007;1:267-273. doi: 10.1007/s12072-007-5001-0.

[43] Hsu YS, Chien RN, Yeh CT, Sheen IS, Chiou HY, Chu CM, et al. Long-term outcome after spontaneous $\mathrm{HBeAg}$ seroconversion in patients with chronic hepatitis B. Hepatology 2002;35:1522-1527. doi: 10.1053/jhep.2002. 33638.

[44] McMahon BJ, Holck P, Bulkow L, Snowball M. Serologic and clinical outcomes of 1536 Alaska Natives chronically infected with hepatitis B virus. Ann Intern Med 2001;135:759-768. doi: 10.7326/0003-4819-135-9200111060-00006

[45] Fattovich G, Giustina G, Schalm SW, Hadziyannis S, Sanchez-Tapias J, Almasio $P$, et al. Occurrence of hepatocellular carcinoma and decompensation in western European patients with cirrhosis type B. The EUROHEP Study Group on Hepatitis B Virus and Cirrhosis. Hepatology 1995;21:77-82.

[46] Fattovich G. Natural history and prognosis of hepatitis B. Semin Liver Dis 2003;23:47-58. doi: 10.1055/s-2003-37590.

[47] Tseng TC, Liu CJ, Yang HC, Su TH, Wang CC, Chen CL, et al. Serum hepatitis $B$ surface antigen levels help predict disease progression in patients with low hepatitis B virus loads. Hepatology 2013;57:441-450. doi: 10. 1002/hep.26041

[48] Tseng TC, Liu CJ, Yang HC, Su TH, Wang CC, Chen CL, et al. High levels of hepatitis $B$ surface antigen increase risk of hepatocellular carcinoma in patients with low HBV load. Gastroenterology 2012;142:1140-1149.e3. doi: $10.1053 /$ j.gastro.2012.02.007.

[49] Dandri M, Locarnini S. New insight in the pathobiology of hepatitis B virus infection. Gut 2012;61 Suppl 1:i6-i17. doi: 10.1136/gutjnl-2012-302056.

[50] Zhang Z, Zhang JY, Wang LF, Wang FS. Immunopathogenesis and prognostic immune markers of chronic hepatitis B virus infection. J Gastroenterol Hepatol 2012;27:223-230. doi: 10.1111/j.1440-1746.2011.06940.x.

[51] Isogawa M, Tanaka Y. Immunobiology of hepatitis B virus infection. Hepatol Res 2015;45:179-189. doi: 10.1111/hepr.12439.

[52] Guidotti LG, Chisari FV. Noncytolytic control of viral infections by the innate and adaptive immune response. Annu Rev Immunol 2001;19:65-91. doi: 10.1146/annurev.immunol.19.1.65.

[53] Bertoletti A, Ferrari C. Innate and adaptive immune responses in chronic hepatitis $B$ virus infections: towards restoration of immune control of viral infection. Gut 2012;61:1754-1764. doi: 10.1136/gutjnl-2011-301073.

[54] Fan R, Sun J, Yuan Q, Xie Q, Bai X, Ning Q, et al. Baseline quantitative hepatitis $B$ core antibody titre alone strongly predicts $\mathrm{HBeAg}$ seroconversion across chronic hepatitis B patients treated with peginterferon or nucleos $(\mathrm{t})$ ide analogues. Gut 2016;65:313-320. doi: 10.1136/gutjnl-2014-308546.

[55] Hou FQ, Song LW, Yuan Q, Fang LL, Ge SX, Zhang J, et al. Quantitative hepatitis $B$ core antibody level is a new predictor for treatment response in $\mathrm{HBeAg}$-positive chronic hepatitis B patients receiving peginterferon. Theranostics 2015;5:218-226. doi: 10.7150/thno.10636.

[56] Lampertico P, Maini M, Papatheodoridis G. Optimal management of hepatitis $B$ virus infection - EASL Special Conference. J Hepatol 2015;63:1238-1253. doi: 10.1016/j.jhep.2015.06.026.

[57] Liaw YF, Kao JH, Piratvisuth T, Chan HL, Chien RN, Liu CJ, et al. Asian-Pacific consensus statement on the management of chronic hepatitis B: a 2012 update. Hepatol Int 2012;6:531-561. doi: 10.1007/s12072-012-9365-4.
[58] Ministry of Health of the People's Republic of China. Updated standards for the diagnosis and treatment of primary liver cancer. Zhonghua Gan Zang Bing Za Zhi 2012;20:419-426.

[59] Wong GL, Chan HL, Tse YK, Chan HY, Tse CH, Lo AO, et al. On-treatment alpha-fetoprotein is a specific tumor marker for hepatocellular carcinoma in patients with chronic hepatitis B receiving entecavir. Hepatology 2014;59: 986-995. doi: 10.1002/hep.26739.

[60] Hann HW, Fu X, Myers RE, Hann RS, Wan S, Kim SH, et al. Predictive value of alpha-fetoprotein in the long-term risk of developing hepatocellular carcinoma in patients with hepatitis B virus infection-results from a clinic-based longitudinal cohort. Eur J Cancer 2012;48:2319-2327. doi: 10.1016/j.ejca. 2012.02.065.

[61] Amaddeo G, Cao Q, Ladeiro Y, Imbeaud S, Nault JC, Jaoui D, et al. Integration of tumour and viral genomic characterizations in HBV-related hepatocellular carcinomas. Gut 2015;64:820-829. doi: 10.1136/gutjnl2013-306228.

[62] Marrero JA, Su GL, Wei W, Emick D, Conjeevaram HS, Fontana RJ, et al. Des-gamma carboxyprothrombin can differentiate hepatocellular carcinoma from nonmalignant chronic liver disease in american patients. Hepatology 2003;37:1114-1121. doi: 10.1053/jhep.2003.50195.

[63] Inagaki Y, Tang W, Makuuchi M, Hasegawa K, Sugawara Y, Kokudo N. Clinical and molecular insights into the hepatocellular carcinoma tumour marker des- $\gamma$-carboxyprothrombin. Liver Int 2011;31:22-35. doi: 10.1111/j. 1478-3231.2010.02348.x

[64] Seo SI, Kim HS, Kim WJ, Shin WG, Kim DJ, Kim KH, et al. Diagnostic value of PIVKA-II and alpha-fetoprotein in hepatitis B virus-associated hepatocellular carcinoma. World J Gastroenterol 2015;21:3928-3935. doi: 10. 3748/wjg.v21.i13.3928.

[65] Wai CT, Greenson JK, Fontana RJ, Kalbfleisch JD, Marrero JA, Conjeevaram $\mathrm{HS}$, et al. A simple noninvasive index can predict both significant fibrosis and cirrhosis in patients with chronic hepatitis C. Hepatology 2003;38:518526. doi: $10.1053 /$ jhep.2003.50346.

[66] Scott DR, Levy MT. Liver transient elastography (Fibroscan): a place in the management algorithms of chronic viral hepatitis. Antivir Ther 2010;15:111. doi: $10.3851 /$ IMP1474.

[67] Shaheen AA, Wan AF, Myers RP. FibroTest and FibroScan for the prediction of hepatitis C-related fibrosis: a systematic review of diagnostic test accuracy. Am J Gastroenterol 2007;102:2589-2600. doi: 10.1111/j.1572-0241. 2007.01466.x.

[68] European Association for Study of Liver; Asociacion Latinoamericana para el Estudio del Higado. EASL-ALEH Clinical Practice Guidelines: Non-invasive tests for evaluation of liver disease severity and prognosis. J Hepatol 2015;63:237-264. doi: 10.1016/j.jhep.2015.04.006.

[69] Review Panel for Liver Stiffness Measurement. Recommendations for the clinical application of transient elastography in liver fibrosis assessment. Zhonghua Gan Zang Bing Za Zhi 2013;21:420-424.

[70] Jia J, Hou J, Ding H, Chen G, Xie Q, Wang Y, et al. Transient elastography compared to serum markers to predict liver fibrosis in a cohort of Chinese patients with chronic hepatitis B. J Gastroenterol Hepatol 2015;30:756762. doi: $10.1111 /$ jgh. 12840 .

[71] Chang TT, Liaw YF, Wu SS, Schiff E, Han KH, Lai CL, et al. Long-term entecavir therapy results in the reversal of fibrosis/cirrhosis and continued histological improvement in patients with chronic hepatitis B. Hepatology 2010;52:886-893. doi: 10.1002/hep.23785.

[72] Marcellin P, Gane E, Buti M, Afdhal N, Sievert W, Jacobson IM, et al. Regression of cirrhosis during treatment with tenofovir disoproxil fumarate for chronic hepatitis B: a 5-year open-label follow-up study. Lancet 2013; 381:468-475. doi: 10.1016/S0140-6736(12)61425-1.

[73] Li W, Zhao ], Zou Z, Liu Y, Li B, Sun Y, et al. Analysis of hepatitis B virus intrahepatic covalently closed circular DNA and serum viral markers in treatment-naive patients with acute and chronic HBV infection. PLoS One 2014;9:e89046. doi: 10.1371/journal.pone.0089046.

[74] Bedossa P, Poynard T. An algorithm for the grading of activity in chronic hepatitis C. The METAVIR Cooperative Study Group. Hepatology 1996;24: 289-293. doi: 10.1002/hep.510240201.

[75] Xu S, Wang Y, Tai DCS, Wang S, Cheng CL, Peng Q, et al. qFibrosis: a fullyquantitative innovative method incorporating histological features to facilitate accurate fibrosis scoring in animal model and chronic hepatitis B patients. J Hepatol 2014;61:260-269. doi: 10.1016/j.jhep.2014.02.015.

[76] Ding H, Ma J], Wang WP, Zeng WJ, Jiang T, Huang B], et al. Assessment of liver fibrosis: the relationship between point shear wave elastography and quantitative histological analysis. J Gastroenterol Hepatol 2015;30:553558. doi: $10.1111 /$ jgh.12789.

[77] Ganem D, Prince AM. Hepatitis B virus infection-natural history and clinical consequences. N Engl J Med 2004;350:1118-1129. doi: 10.1056/ NEJMra031087.

[78] European Association For The Study Of The Liver. EASL clinical practice guidelines: Management of chronic hepatitis B virus infection. J Hepatol 2012;57:167-185. doi: 10.1016/j.jhep.2012.02.010. 
[79] Oliveri F, Coco B, Ciccorossi P, Colombatto P, Romagnoli V, Cherubini B, et al. Liver stiffness in the hepatitis B virus carrier: a non-invasive marker of liver disease influenced by the pattern of transaminases. World J Gastroenterol 2008;14:6154-6162. doi: 10.3748/wjg.14.6154

[80] Chinese Society of Hepatology and Chinese Society of Infectious Diseases, Chinese Medical Association. The guideline of prevention and treatment for chronic hepatitis B (2010 version). Zhonghua Gan Zang Bing Za Zhi 2011; 19:13-24. doi: 10.3760/cma.j.issn.1007-3418.2011.01.007.

[81] Arvaniti V, D'Amico G, Fede G, Manousou P, Tsochatzis E, Pleguezuelo M, et al. Infections in patients with cirrhosis increase mortality four-fold and should be used in determining prognosis. Gastroenterology 2010;139: 1246-1256.e5. doi: 10.1053/j.gastro.2010.06.019.

[82] Tsochatzis EA, Bosch J, Burroughs AK. Liver cirrhosis. Lancet 2014;383: 1749-1761. doi: 10.1016/S0140-6736(14)60121-5.

[83] Caviglia GP, Abate ML, Pellicano R, Smedile A. Chronic hepatitis B therapy: available drugs and treatment guidelines. Minerva Gastroenterol Dietol 2015;61:61-70.

[84] Vallet-Pichard A, Pol S. Hepatitis B virus treatment beyond the guidelines: special populations and consideration of treatment withdrawal. Therap Adv Gastroenterol 2014;7:148-155. doi: 10.1177/1756283X14524614.

[85] Tang CM, Yau TO, Yu J. Management of chronic hepatitis B infection: current treatment guidelines, challenges, and new developments. World J Gastroenterol 2014;20:6262-6278. doi: 10.3748/wjg.v20.i20.6262.

[86] Zhao H, Kurbanov F, Wan MB, Yin YK, Niu JQ, Hou JL, et al. Genotype B and younger patient age associated with better response to low-dose therapy: a trial with pegylated/nonpegylated interferon-alpha-2b for hepatitis $B$ antigen-positive patients with chronic hepatitis B in China. Clin Infect Dis 2007;44:541-548. doi: 10.1086/511042.

[87] Liaw YF, Jia JD, Chan HL, Han KH, Tanwandee T, Chuang WL, et al. Shorter durations and lower doses of peginterferon alfa-2a are associated with inferior hepatitis $B$ e antigen seroconversion rates in hepatitis $B$ virus genotypes B or C. Hepatology 2011;54:1591-1599. doi: 10.1002/hep.24555.

[88] Buster EH, Flink HJ, Cakaloglu Y, Simon K, Trojan J, Tabak F, et al. Sustained $\mathrm{HBeAg}$ and HBsAg loss after long-term follow-up of HBeAg-positive patients treated with peginterferon alpha-2b. Gastroenterology 2008;135:459467. doi: $10.1053 /$ j.gastro.2008.05.031.

[89] Marcellin P, Bonino F, Yurdaydin C, Hadziyannis S, Moucari R, Kapprell HP, et al. Hepatitis B surface antigen levels: association with 5 -year response to peginterferon alfa-2a in hepatitis $\mathrm{B}$ e-antigen-negative patients. Hepatol Int 2013;7:88-97. doi: 10.1007/s12072-012-9343-x.

[90] Lampertico P, Viganò M, Colombo M. Treatment of HBeAg-negative chronic hepatitis B with pegylated interferon. Liver Int 2011;31 Suppl 1:90-94. doi: 10.1111/j.1478-3231.2010.02386.x.

[91] Lampertico P, Viganò M, Di Costanzo GG, Sagnelli E, Fasano M, Di Marco V, et al. Randomised study comparing 48 and 96 weeks peginterferon $\alpha-2 a$ therapy in genotype D HBeAg-negative chronic hepatitis B. Gut 2013;62: 290-298. doi: 10.1136/gutjnl-2011-301430.

[92] Kim V, Abreu RM, Nakagawa DM, Baldassare RM, Carrilho FJ, Ono SK. Pegylated interferon alfa for chronic hepatitis $B$ : systematic review and metaanalysis. J Viral Hepat 2016;23:154-169. doi: 10.1111/jvh.12418.

[93] Wong GL, Wong VW, Chan HL. Combination therapy of interferon and nucleotide/nucleoside analogues for chronic hepatitis B. J Viral Hepat 2014;21: 825-834. doi: 10.1111/jvh.12341.

[94] Marcellin P, Ahn SH, Ma X, Caruntu F, Tak WY, Elkashab M, et al. Hbsag loss with tenofovir disoproxil fumarate (TDF) plus peginterferon alfa $2 A(P E G)$ combination therapy in chronic hepatitis B (CHB). Hepatol Int 2015;9:S40.

[95] Xie Q, Zhou H, Bai X, Wu S, Chen JJ, Sheng J, et al. A randomized, openlabel clinical study of combined pegylated interferon Alfa-2a (40KD) and entecavir treatment for hepatitis B " $\mathrm{e}$ " antigen-positive chronic hepatitis B. Clin Infect Dis 2014;59:1714-1723. doi: 10.1093/cid/ciu702.

[96] Chi H, Xie Q, Zhang NP, Qi X, Liang C, Guo S, et al. Addition of peginterferon alfa-2b during long-term nucleos(t)ide analogue therapy increases $\mathrm{HBeAg}$ seroconversion and $\mathrm{HBsAg}$ decline - week 48 results from a multicenter randomized controlled trial (PEGON Study). Hepatology 2014;60:1106A.

[97] Ning Q, Han M, Sun $Y$, Jiang J, Tan D, Hou J, et al. Switching from entecavir to PegIFN alfa-2a in patients with $\mathrm{HBeAg}$-positive chronic hepatitis $\mathrm{B}$ : a randomised open-label trial (OSST trial). J Hepatol 2014;61:777-784. doi: 10.1016/j.jhep.2014.05.044.

[98] Hu P, Jia S, Zhang WH, Gong G, Li Y, Chen $X$, et al. A multi-center randomized study on the efficacy and safety of switching to peginterferon $\alpha-2 a$ (40KD) for 48 or 96 weeks in HBeAg positive CHB patients with a prior NUC history for 1 to 3 years: an interim analysis of NEW SWITCH study. Hepatology 2014;60:1273A-1274A.

[99] Brouwer WP, Xie Q, Sonneveld MJ, Zhang N, Zhang Q, Tabak F, et al. Adding pegylated interferon to entecavir for hepatitis $B$ e antigen-positive chronic hepatitis B: A multicenter randomized trial (ARES study). Hepatology 2015; 61:1512-1522. doi: 10.1002/hep.27586.

[100] Li G], Yu YQ, Chen SL, Fan P, Shao LY, Chen JZ, et al. Sequential combination therapy with pegylated interferon leads to loss of hepatitis $B$ surface antigen and hepatitis $\mathrm{B}$ e antigen $(\mathrm{HBeAg}$ ) seroconversion in $\mathrm{HBeAg-pos-}$ itive chronic hepatitis $B$ patients receiving long-term entecavir treatment. Antimicrob Agents Chemother 2015;59:4121-4128. doi: 10.1128/AAC. 00249-15.

[101] Sonneveld MJ, Hansen BE, Piratvisuth $T$, Jia JD, Zeuzem S, Gane E, et al. Response-guided peginterferon therapy in hepatitis $B$ e antigen-positive chronic hepatitis B using serum hepatitis B surface antigen levels. Hepatology 2013;58:872-880. doi: 10.1002/hep.26436.

[102] Sarri G, Westby M, Bermingham S, Hill-Cawthorne G, Thomas H; Guideline Development Group. Diagnosis and management of chronic hepatitis B in children, young people, and adults: summary of NICE guidance. BMJ 2013 346:f3893. doi: 10.1136/bmj.f3893.

[103] Rijckborst V, Hansen BE, Ferenci P, Brunetto MR, Tabak F, Cakaloglu Y, et al. Validation of a stopping rule at week 12 using HBsAg and HBV DNA for HBeAg-negative patients treated with peginterferon alfa-2a. J Hepatol 2012;56:1006-1011. doi: 10.1016/j.jhep.2011.12.007.

[104] Chang TT, Gish RG, de Man R, Gadano A, Sollano J, Chao YC, et al. A comparison of entecavir and lamivudine for HBeAg-positive chronic hepatitis B. N Engl J Med 2006;354:1001-1010. doi: 10.1056/NEJMoa051285.

[105] Lai CL, Shouval D, Lok AS, Chang TT, Cheinquer H, Goodman Z, et al. Entecavir versus lamivudine for patients with $\mathrm{HBeAg}$-negative chronic hepatitis B. N Engl J Med 2006;354:1011-1020. doi: 10.1056/NEJMoa051287.

[106] Chang TT, Lai CL, Kew Yoon S, Lee SS, Coelho HS, Carrilho FJ, et al. Entecavir treatment for up to 5 years in patients with hepatitis $B$ e antigenpositive chronic hepatitis B. Hepatology 2010;51:422-430. doi: 10. 1002/hep. 23327

[107] Tenney DJ, Rose RE, Baldick CJ, Pokornowski KA, Eggers BJ, Fang J, et al. Long-term monitoring shows hepatitis $B$ virus resistance to entecavir in nucleoside-naïve patients is rare through 5 years of therapy. Hepatology 2009;49:1503-1514. doi: 10.1002/hep.22841.

[108] Lok AS. Hepatitis: Long-term therapy of chronic hepatitis B reverses cirrhosis. Nat Rev Gastroenterol Hepatol 2013;10:199-200. doi: 10. 1038/nrgastro.2013.13.

[109] Marcellin P, Heathcote EJ, Buti M, Gane E, de Man RA, Krastev Z, et al. Tenofovir disoproxil fumarate versus adefovir dipivoxil for chronic hepatitis B. N Engl J Med 2008;359:2442-2455. doi: 10.1056/NEJMoa0802878.

[110] Marcellin P, Gane EJ, Flisiak R, Trinh HN, Petersen J, Gurel S, et al. Long term treatment with tenofovir disoproxil fuma-rate for chronic hepatitis $b$ infection is safe and well tolerated and associated with durable virologic response with no detectable resistance: 8 year results from two phase 3 trials. Hepatology 2014;60:313A-314A.

[111] Fung S, Kwan P, Fabri M, Horban A, Pelemis M, Hann HW, et al. Randomized comparison of tenofovir disoproxil fumarate vs emtricitabine and tenofovir disoproxil fumarate in patients with lamivudine-resistant chronic hepatitis B. Gastroenterology 2014;146:980-988. doi: 10.1053/j.gastro.2013.12.028.

[112] Lim YS, Yoo BC, Byun KS, Kwon SY, Kim YJ, An J, et al. Tenofovir monotherapy versus tenofovir and entecavir combination therapy in adefovir-resistant chronic hepatitis $B$ patients with multiple drug failure: results of a randomised trial. Gut 2016;65:1042-1051. doi: 10.1136/gutjnl-2014-308435.

[113] Patterson SJ, George J, Strasser SI, Lee AU, Sievert W, Nicoll AJ, et al. Tenofovir disoproxil fumarate rescue therapy following failure of both lamivudine and adefovir dipivoxil in chronic hepatitis B. Gut 2011;60:247-254. doi: 10.1136/gut.2010.223206.

[114] Berg T, Zoulim F, Moeller B, Trinh H, Marcellin P, Chan S, et al. Long-term efficacy and safety of emtricitabine plus tenofovir DF vs. tenofovir DF monotherapy in adefovir-experienced chronic hepatitis B patients. J Hepatol 2014;60:715-722. doi: 10.1016/j.jhep.2013.11.024.

[115] Hou J, Yin YK, Xu D, Tan D, Niu J, Zhou X, et al. Telbivudine versus lamivudine in Chinese patients with chronic hepatitis $B$ : Results at 1 year of a randomized, double-blind trial. Hepatology 2008;47:447-454. doi: 10. 1002/hep.22075.

[116] Liaw YF, Gane E, Leung N, Zeuzem S, Wang Y, Lai CL, et al. 2-Year GLOBE trial results: telbivudine Is superior to lamivudine in patients with chronic hepatitis B. Gastroenterology 2009;136:486-495. doi: 10.1053/j.gastro. 2008.10.026.

[117] Sun J, Xie Q, Tan D, Ning Q, Niu J, Bai X, et al. The 104-week efficacy and safety of telbivudine-based optimization strategy in chronic hepatitis $B$ patients: a randomized, controlled study. Hepatology 2014;59:12831292. doi: 10.1002/hep.26885.

[118] Marcellin P, Chang TT, Lim SG, Sievert W, Tong M, Arterburn S, et al. Longterm efficacy and safety of adefovir dipivoxil for the treatment of hepatitis $B$ e antigen-positive chronic hepatitis B. Hepatology 2008;48:750-758. doi: 10.1002/hep. 22414.

[119] Zeng M, Mao Y, Yao G, Wang H, Hou J, Wang Y, et al. A double-blind randomized trial of adefovir dipivoxil in Chinese subjects with HBeAg-positive chronic hepatitis B. Hepatology 2006;44:108-116. doi: 10.1002/hep.21225.

[120] Hadziyannis SJ, Tassopoulos NC, Heathcote EJ, Chang TT, Kitis G, Rizzetto $\mathrm{M}$, et al. Long-term therapy with adefovir dipivoxil for $\mathrm{HBeAg}$-negative chronic hepatitis B for up to 5 years. Gastroenterology 2006;131:17431751. doi: 10.1053/j.gastro.2006.09.020. 
[121] Lampertico $P$, Viganò $M$, Manenti $E$, Iavarone $M$, Sablon E, Colombo M. Low resistance to adefovir combined with lamivudine: a 3-year study of 145 lamivudine-resistant hepatitis B patients. Gastroenterology 2007;133: 1445-1451. doi: 10.1053/j.gastro.2007.08.079.

[122] Yao GB, Zhu M, Cui ZY, Wang BE, Yao JL, Zeng MD. A 7-year study of lamivudine therapy for hepatitis $B$ virus e antigen-positive chronic hepatitis B patients in China. J Dig Dis 2009;10:131-137. doi: 10.1111/j.17512980.2009.00375.x.

[123] Liaw YF, Sung J], Chow WC, Farrell G, Lee CZ, Yuen H, et al. Lamivudine for patients with chronic hepatitis $B$ and advanced liver disease. N Engl J Med 2004;351:1521-1531. doi: 10.1056/NEJMoa033364.

[124] Chen $\mathrm{CH}_{\text {, Lin } \mathrm{CL}}$, Hu TH, Hung $\mathrm{CH}$, Tseng PL, Wang JH, et al. Entecavir vs. lamivudine in chronic hepatitis $\mathrm{B}$ patients with severe acute exacerbation and hepatic decompensation. J Hepatol 2014;60:1127-1134. doi: 10. 1016/j.jhep.2014.02.013.

[125] Lau GK, Piratvisuth T, Luo KX, Marcellin P, Thongsawat S, Cooksley G, et al. Peginterferon Alfa-2a, lamivudine, and the combination for $\mathrm{HBeAg}$-positive chronic hepatitis B. N Engl J Med 2005;352:2682-2695. doi: 10. 1056/NEJMoa043470.

[126] Janssen HL, van Zonneveld M, Senturk H, Zeuzem S, Akarca US, Cakaloglu $Y$, et al. Pegylated interferon alfa-2b alone or in combination with lamivudine for HBeAg-positive chronic hepatitis B: a randomised trial. Lancet 2005;365:123-129. doi: 10.1016/S0140-6736(05)17701-0.

[127] Lai CL, Chien RN, Leung NW, Chang TT, Guan R, Tai DI, et al. A one-year trial of lamivudine for chronic hepatitis B. Asia Hepatitis Lamivudine Study Group. N Engl J Med 1998;339:61-68. doi: 10.1056/NEJM199807093390201.

[128] Dienstag JL, Schiff ER, Wright TL, Perrillo RP, Hann HW, Goodman Z, et al. Lamivudine as initial treatment for chronic hepatitis B in the United States. N Engl J Med 1999;341:1256-1263. doi: 10.1056/NEJM199910213411702.

[129] Lai CL, Gane E, Liaw YF, Hsu CW, Thongsawat S, Wang Y, et al. Telbivudine versus lamivudine in patients with chronic hepatitis B. N Engl J Med 2007; 357:2576-2588. doi: 10.1056/NEJMoa066422.

[130] Marcellin P, Chang TT, Lim SG, Tong MJ, Sievert W, Shiffman ML, et al. Adefovir dipivoxil for the treatment of hepatitis $\mathrm{B}$ e antigen-positive chronic hepatitis B. N Engl J Med 2003;348:808-816. doi: 10.1056/NEJMoa020681.

[131] Gish RG, Lok AS, Chang TT, de Man RA, Gadano A, Sollano J, et al. Entecavir therapy for up to 96 weeks in patients with $\mathrm{HBeAg}$-positive chronic hepatitis B. Gastroenterology 2007;133:1437-1444. doi: 10.1053/j.gastro.2007. 08.025.

[132] Minde Z, Yimin M, Guangbi Y, JinLin H, Hao W, Hong R, et al. Five years of treatment with adefovir dipivoxil in Chinese patients with $\mathrm{HBeAg}$-positive chronic hepatitis B. Liver Int 2012;32:137-146. doi: 10.1111/j.14783231.2011.02641.x.

[133] Marcellin P, Lau GK, Bonino F, Farci P, Hadziyannis S, Jin R, et al. Peginterferon alfa-2a alone, lamivudine alone, and the two in combination in patients with HBeAg-negative chronic hepatitis B. N Engl J Med 2004; 351:1206-1217. doi: 10.1056/NEJMoa040431.

[134] Tassopoulos NC, Volpes R, Pastore G, Heathcote J, Buti M, Goldin RD, et al. Efficacy of lamivudine in patients with hepatitis $B$ e antigen-negative/hepatitis B virus DNA-positive (precore mutant) chronic hepatitis B. Lamivudine Precore Mutant Study Group. Hepatology 1999;29:889-896. doi: 10. 1002/hep.510290321.

[135] Hadziyannis SJ, Tassopoulos NC, Heathcote EJ, Chang TT, Kitis G, Rizzetto $M$, et al. Adefovir dipivoxil for the treatment of hepatitis $B$ e antigennegative chronic hepatitis B. N Engl J Med 2003;348:800-807. doi: 10. 1056/NEJMoa021812.

[136] Marcellin P, Bonino F, Lau GK, Farci P, Yurdaydin C, Piratvisuth T, et al. Sustained response of hepatitis $B$ e antigen-negative patients 3 years after treatment with peginterferon alpha-2a. Gastroenterology 2009;136: 2169-2179.e4. doi: 10.1053/j.gastro.2009.03.006.

[137] Experts Attending the Discussion on Hepatitis B Virus Drug Resistance. Development and management of drug resistance to nucleoside/nucleotide analogues in patients with chronic hepatitis B. Chin J Viral Dis 2013;3:1-11. doi: $10.16505 / j .2095-0136.2013 .01 .008$.

[138] Sun J, Hou JL, Xie O, Li XH, Zhang JM, Wang YM, et al. Randomised clinical trial: efficacy of peginterferon alfa-2a in HBeAg positive chronic hepatitis B patients with lamivudine resistance. Aliment Pharmacol Ther 2011;34: 424-431. doi: 10.1111/j.1365-2036.2011.04750.x.

[139] Yapali S, Talaat N, Fontana RJ, Oberhelman K, Lok AS. Outcomes of patients with chronic hepatitis B who do not meet criteria for antiviral treatment at presentation. Clin Gastroenterol Hepatol 2015;13:193-201.e1. doi: 10. 1016/j.cgh.2014.07.019.

[140] Lok AS, McMahon B]. Chronic hepatitis B: update 2009. Hepatology 2009; 50:661-662. doi: 10.1002/hep.23190.

[141] Liang X, Cheng J, Sun Y, Chen X, Li T, Wang H, et al. Randomized, three-arm study to optimize lamivudine efficacy in hepatitis B e antigen-positive chronic hepatitis B patients. J Gastroenterol Hepatol 2015;30:748-755. doi: $10.1111 /$ jgh.12835.

[142] Reijnders JG, Perquin MJ, Zhang N, Hansen BE, Janssen HL. Nucleos(t)ide analogues only induce temporary hepatitis $\mathrm{B}$ e antigen seroconversion in most patients with chronic hepatitis B. Gastroenterology 2010;139:491498. doi: 10.1053/j.gastro.2010.03.059.

[143] Chi H, Hansen BE, Yim C, Arends P, Abu-Amara M, van der Eijk AA, et al. Reduced risk of relapse after long-term nucleos(t)ide analogue consolidation therapy for chronic hepatitis B. Aliment Pharmacol Ther 2015;41:867876. doi: 10.1111/apt.13150.

[144] Ryu SH, Chung YH, Choi MH, Kim JA, Shin JW, Jang MK, et al. Long-term additional lamivudine therapy enhances durability of lamivudine-induced HBeAg loss: a prospective study. J Hepatol 2003;39:614-619. doi: 10. 1016/S0168-8278(03)00394-5

[145] Wang Y, Thongsawat S, Gane EJ, Liaw YF, Jia J, Hou J, et al. Efficacy and safety of continuous 4-year telbivudine treatment in patients with chronic hepatitis B. J Viral Hepat 2013;20:e37-e46. doi: 10.1111/jvh.12025.

[146] Seto WK, Hui AJ, Wong VW, Wong GL, Liu KS, Lai CL, et al. Treatment cessation of entecavir in Asian patients with hepatitis $B$ e antigen negative chronic hepatitis B: a multicentre prospective study. Gut 2015;64:667672. doi: 10.1136/gutjnl-2014-307237.

[147] Jeng WJ, Sheen IS, Chen YC, Hsu CW, Chien RN, Chu CM, et al. Off-therapy durability of response to entecavir therapy in hepatitis $\mathrm{B}$ e antigen-negative chronic hepatitis B patients. Hepatology 2013;58:1888-1896. doi: 10. 1002/hep.26549.

[148] Buster EH, Hansen BE, Buti M, Delwaide ], Niederau C, Michielsen PP, et al. Peginterferon alpha- $2 b$ is safe and effective in HBeAg-positive chronic hepatitis $B$ patients with advanced fibrosis. Hepatology $2007 ; 46: 388-394$. doi: 10.1002/hep.21723.

[149] Cho JY, Paik YH, Sohn W, Cho HC, Gwak GY, Choi MS, et al. Patients with chronic hepatitis $B$ treated with oral antiviral therapy retain a higher risk for HCC compared with patients with inactive stage disease. Gut 2014;63: 1943-1950. doi: 10.1136/gutjnl-2013-306409.

[150] Yang YJ, Shim JH, Kim KM, Lim YS, Lee HC. Assessment of current criteria for primary nonresponse in chronic hepatitis $\mathrm{B}$ patients receiving entecavir therapy. Hepatology 2014;59:1303-1310. doi: 10.1002/hep.26910.

[151] Liu CJ, Chen PJ, Chen DS, Kao JH. Hepatitis B virus reactivation in patients receiving cancer chemotherapy: natural history, pathogenesis, and management. Hepatol Int 2013;7:316-326. doi: 10.1007/s12072-011-9279-6.

[152] Loomba R, Rowley A, Wesley R, Liang TJ, Hoofnagle JH, Pucino F, et al. Systematic review: the effect of preventive lamivudine on hepatitis $B$ reactivation during chemotherapy. Ann Intern Med 2008;148:519-528. doi: 10.7326/0003-4819-148-7-200804010-00008

[153] Li HR, Huang JJ, Guo HQ, Zhang X, Xie Y, Zhu HL, et al. Comparison of entecavir and lamivudine in preventing hepatitis $B$ reactivation in lymphoma patients during chemotherapy. J Viral Hepat 2011;18:877-883. doi: 10.1111/j.1365-2893.2010.01386.x.

[154] Perrillo RP, Gish R, Falck-Ytter YT. American Gastroenterological Association Institute technical review on prevention and treatment of hepatitis $B$ virus reactivation during immunosuppressive drug therapy. Gastroenterology 2015;148:221-244.e3. doi: 10.1053/j.gastro.2014.10.038.

[155] Hwang JP, Lok AS. Management of patients with hepatitis B who require immunosuppressive therapy. Nat Rev Gastroenterol Hepatol 2014;11: 209-219. doi: 10.1038/nrgastro.2013.216.

[156] European Association for Study of Liver. EASL Recommendations on Treatment of Hepatitis C 2015. J Hepatol 2015;63:199-236. doi: 10.1016/j. jhep.2015.03.025.

[157] Konstantinou D, Deutsch M. The spectrum of HBV/HCV coinfection: epidemiology, clinical characteristics, viralinteractions and management. Ann Gastroenterol 2015;28:221-228.

[158] Liu JY, Sheng YJ, Hu HD, Zhong Q, Wang J, Tong SW, et al. The influence of hepatitis $B$ virus on antiviral treatment with interferon and ribavirin in Asian patients with hepatitis $C$ virus/hepatitis $B$ virus coinfection: a metaanalysis. Virol J 2012;9:186. doi: 10.1186/1743-422X-9-186.

[159] Kosi L, Reiberger T, Payer BA, Grabmeier-Pfistershammer K, Strassl R, Rieger $A$, et al. Five-year on-treatment efficacy of lamivudine-, tenofovirand tenofovir + emtricitabine-based HAART in HBV-HIV-coinfected patients. J Viral Hepat 2012;19:801-810. doi: 10.1111/j.1365-2893.2012.01601.x.

[160] Antonucci G, Mazzotta F, Angeletti C, Girardi E, Puoti M, De Stefano G, et al. Access to treatment for $\mathrm{HBV}$ infection and its consistency with 2008 European guidelines in a multicentre cross-sectional study of HIV/HBV co-infected patients in Italy. BMC Res Notes 2013;6:153. doi: 10.1186/1756-05006-153.

[161] Zoutendijk R, Zaaijer HL, de Vries-Sluijs TE, Reijnders JG, Mulder JW, Kroon $\mathrm{FP}$, et al. Hepatitis B surface antigen declines and clearance during longterm tenofovir therapy in patients coinfected with HBV and HIV. J Infect Dis 2012;206:974-980. doi: 10.1093/infdis/jis439.

[162] Zhang Y, Hu XY, Zhong S, Yang F, Zhou TY, Chen G, et al. Entecavir vs lamivudine therapy for naïve patients with spontaneous reactivation of hepatitis B presenting as acute-on-chronic liver failure. World J Gastroenterol 2014;20:4745-4752. doi: 10.3748/wjg.v20.i16.4745.

[163] Garg H, Sarin SK, Kumar M, Garg V, Sharma BC, Kumar A. Tenofovir improves the outcome in patients with spontaneous reactivation of 
hepatitis B presenting as acute-on-chronic liver failure. Hepatology 2011; 53:774-780. doi: 10.1002/hep.24109.

[164] Yu S, Jianqin $H$, Wei W, Jianrong $H$, Yida $Y$, Jifang $S$, et al. The efficacy and safety of nucleos(t)ide analogues in the treatment of HBV-related acuteon-chronic liver failure: a meta-analysis. Ann Hepatol 2013;12:364-372.

[165] Zhang X, An Y, Jiang X, Xu M, Xu L, Chen S, et al. Entecavir versus Lamivudine therapy for patients with chronic hepatitis B-associated liver failure: a meta-analysis. Hepat Mon 2014;14:e19164. doi: 10.5812/hepatmon. 19164.

[166] Xie F, Yan L, Lu J, Zheng T, Shi C, Ying J, et al. Effects of nucleoside analogue on patients with chronic hepatitis B-associated liver failure: meta-analysis. PLoS One 2013;8:e54773. doi: 10.1371/journal.pone.0054773.

[167] Sun P, Dong X, Cheng X, Hu Q, Zheng Q. Nucleot(s)ide analogues for hepatitis $\mathrm{B}$ virus-related hepatocellular carcinoma after curative treatment: systematic review and meta-analysis. PLoS One 2014;9:e102761. doi: 10. 1371/journal.pone.0102761.

[168] Yin J, Li N, Han Y, Xue J, Deng Y, Shi J, et al. Effect of antiviral treatment with nucleotide/nucleoside analogs on postoperative prognosis of hepatitis B virus-related hepatocellular carcinoma: a two-stage longitudinal clinical study. J Clin Oncol 2013;31:3647-3655. doi: 10.1200/JCO.2012.48. 5896.

[169] Cholongitas E, Papatheodoridis GV. High genetic barrier nucleos(t)ide analogue(s) for prophylaxis from hepatitis B virus recurrence after liver transplantation: a systematic review. Am J Transplant 2013;13:353-362. doi: 10.1111/j.1600-6143.2012.04315.x.

[170] Yi NJ, Choi JY, Suh KS, Cho JY, Baik M, Hong G, et al. Post-transplantation sequential entecavir monotherapy following 1-year combination therapy with hepatitis B immunoglobulin. J Gastroenterol 2013;48:1401-1410. doi: 10.1007/s00535-013-0761-x.

[171] Teperman LW, Poordad F, Bzowej N, Martin P, Pungpapong S, Schiano T, et al. Randomized trial of emtricitabine/tenofovir disoproxil fumarate after hepatitis B immunoglobulin withdrawal after liver transplantation. Liver Transpl 2013;19:594-601. doi: 10.1002/It.23628.

[172] Lai CL, Yuen MF. Prevention of hepatitis B virus-related hepatocellular carcinoma with antiviral therapy. Hepatology 2013;57:399-408. doi: 10. 1002/hep.25937.

[173] Bzowej NH. Optimal Management of the Hepatitis B Patient Who Desires Pregnancy or Is Pregnant. Curr Hepat Rep 2012;11:82-89. doi: 10. 1007/s11901-012-0130-x.

[174] Pan CQ, Duan ZP, Bhamidimarri KR, Zou HB, Liang XF, Li J, et al. An algorithm for risk assessment and intervention of mother to child transmission of hepatitis B virus. Clin Gastroenterol Hepatol 2012;10:452-459. doi: 10. 1016/j.cgh.2011.10.041.

[175] Zhang H, Pan CQ, Pang Q, Tian R, Yan M, Liu X. Telbivudine or lamivudine use in late pregnancy safely reduces perinatal transmission of hepatitis $B$ virus in real-life practice. Hepatology 2014;60:468-476. doi: 10.1002/hep.27034

[176] Greenup AJ, Tan PK, Nguyen V, Glass A, Davison S, Chatterjee U, et al. Efficacy and safety of tenofovir disoproxil fumarate in pregnancy to prevent perinatal transmission of hepatitis B virus. J Hepatol 2014;61: 502-507. doi: 10.1016/j.jhep.2014.04.038.

[177] Sarkar M, Terrault NA. Ending vertical transmission of hepatitis B: the third trimester intervention. Hepatology 2014;60:448-451. doi: 10.1002/hep. 27145.

[178] Della Corte C, Nobili V, Comparcola D, Cainelli F, Vento S. Management of chronic hepatitis B in children: an unresolved issue. J Gastroenterol Hepatol 2014;29:912-919. doi: 10.1111/jgh.12550.

[179] Saadah OI, Sindi HH, Bin-Talib Y, Al-Harthi S, Al-Mughales J. Entecavir treatment of children 2-16 years of age with chronic hepatitis $B$ infection. Arab J Gastroenterol 2012;13:41-44. doi: 10.1016/j.ajg.2012.04.001.

[180] Jonas MM, Chang MH, Sokal E, Schwarz KB, Kelly D, Kim KM, et al. Randomized, controlled trial of entecavir versus placebo in children with hepatitis $B$ envelope antigen-positive chronic hepatitis B. Hepatology 2016;63:377387. doi: $10.1002 /$ hep.28015. 